\title{
RESEARCH
}

Open Access

\section{A multi-purpose National Forest Inventory in Bangladesh: design, operationalisation and key results}

Matieu Henry ${ }^{1 *}$ (D), Zaheer lqbal ${ }^{2},{\text { Kristofer Johnson }{ }^{1}, \text { Mariam Akhter }^{2}, \text { Liam Costello }}^{1,3}$, Charles Scott $^{4}$, Rashed Jalal ${ }^{1}$, Md. Akhter Hossain ${ }^{5}$, Nikhil Chakma ${ }^{1,6}$, Olaf Kuegler $^{4}$, Hossain Mahmood $^{7}$, Rajib Mahamud ${ }^{1}$, Mohammad Raqibul Hasan Siddique ${ }^{7}$, Khaled Misbahuzzaman ${ }^{5}$, Mohammad Main Uddin ${ }^{5,8}$, Mohammed Al Amin ${ }^{5}$, Farid Uddin Ahmed ${ }^{9}$, Gael Sola ${ }^{1}$, Md. Baktiar Siddiqui ${ }^{2}$, Luca Birigazzi ${ }^{1,10}$, Mahmudur Rahmann ${ }^{11}$, llias Animon , Saimunnahar Ritu', Laskar Muqsudur Rahman', Aminul Islam², Heather Hayden ${ }^{4}$, Frida Sidik², Mondal Falgoonee Kumar ${ }^{1}$, Rakibul Hassan Mukul ${ }^{2}$, Hossain Nishad ${ }^{2}$, Ariful Hoque Belal ${ }^{2}$, Asif Reza Anik ${ }^{13}$, Abdul Khaleque ${ }^{14}$, Md. Shaheduzzaman ${ }^{1}$, Syed Shahadat Hossain ${ }^{15}$, Tariq Aziz², Md. Tauhidor Rahaman², Ruhul Mohaiman ${ }^{2}$, Patrick Meyer ${ }^{16}$, Purnata Chakma ${ }^{1}$, A. Z. M. Manzoor Rashid ${ }^{17}$, Sourav Das ${ }^{18}$, Shrabanti Hira', Mohammed Jashimuddin ${ }^{5}$, Mohammad Mahfuzur Rahman ${ }^{5}$, Karl Wurster ${ }^{16}$, Sarder Nasir Uddin ${ }^{19}$, Abul Kalam Azad ${ }^{20}$, S. M. Zahirul Islam²0 and Laurent Saint-André21

\begin{abstract}
Background: National forest inventory and forest monitoring systems are more important than ever considering continued global degradation of trees and forests. These systems are especially important in a country like Bangladesh, which is characterised by a large population density, climate change vulnerability and dependence on natural resources. With the aim of supporting the Government's actions towards sustainable forest management through reliable information, the Bangladesh Forest Inventory (BFI) was designed and implemented through three components: biophysical inventory, socio-economic survey and remote sensing-based land cover mapping. This article documents the approach undertaken by the Forest Department under the Ministry of Environment, Forests and Climate Change to establish the BFI as a multipurpose, efficient, accurate and replicable national forest assessment. The design, operationalization and some key results of the process are presented.
\end{abstract}

Methods: The BFI takes advantage of the latest and most well-accepted technological and methodological approaches. Importantly, it was designed through a collaborative process which drew from the experience and knowledge of multiple national and international entities. Overall, 1781 field plots were visited, 6400 households were surveyed, and a national land cover map for the year 2015 was produced. Innovative technological enhancements include a semi-automated segmentation approach for developing the wall-to-wall land cover map, an object-based national land characterisation system, consistent estimates between sample-based and mapped land cover areas, use of mobile apps for tree species identification and data collection, and use of differential global positioning system for referencing plot centres.

(Continued on next page)

\footnotetext{
* Correspondence: matieu.henry@fao.org

${ }^{1}$ Food and Agriculture Organization of the United Nations, Viale delle Terme di Caracalla, 00153 Rome, Italy

Full list of author information is available at the end of the article
}

\section{Springer Open}

(c) The Author(s). 2021 Open Access This article is licensed under a Creative Commons Attribution 4.0 International License, which permits use, sharing, adaptation, distribution and reproduction in any medium or format, as long as you give appropriate credit to the original author(s) and the source, provide a link to the Creative Commons licence, and indicate if changes were made. The images or other third party material in this article are included in the article's Creative Commons licence, unless indicated otherwise in a credit line to the material. If material is not included in the article's Creative Commons licence and your intended use is not permitted by statutory regulation or exceeds the permitted use, you will need to obtain permission directly from the copyright holder. To view a copy of this licence, visit http://creativecommons.org/licenses/by/4.0/. 
(Continued from previous page)

Results: Seven criteria, and multiple associated indicators, were developed for monitoring progress towards sustainable forest management goals, informing management decisions, and national and international reporting needs. A wide range of biophysical and socioeconomic data were collected, and in some cases integrated, for estimating the indicators.

Conclusions: The BFI is a new information source tool for helping guide Bangladesh towards a sustainable future. Reliable information on the status of tree and forest resources, as well as land use, empowers evidence-based decision making across multiple stakeholders and at different levels for protecting natural resources. The integrated socioeconomic data collected provides information about the interactions between people and their tree and forest resources, and the valuation of ecosystem services. The BFI is designed to be a permanent assessment of these resources, and future data collection will enable monitoring of trends against the current baseline. However, additional institutional support as well as continuation of collaboration among national partners is crucial for sustaining the BFI process in future.

Keywords: South-Asia, Forest monitoring, Innovation, Remote sensing, Socio-economic, Partnership, Ecosystem services, Carbon sequestration

\section{Background}

Forest resource monitoring has long been applied for managing natural resources and is perhaps more important now than ever. Over the past 25 years, the world's forest area continues to decline, with a net loss of some 129 million ha (FAO 2015a). Although the annual rate of deforestation has slowed during the period 20102015 , land resources are increasingly being degraded and the need for quantitative and spatial information has increased (Dubovyk 2017).

The Sustainable Development Goals (SDG) (UN 2015), as well as multilateral environmental agreements, recognize forests as key ecosystems for the sustainability of our societies. The role of trees and forests is increasingly recognized for the multiple services they provide. However, the capacity to collect, compile and analyse data, and to generate and disseminate forest related information needs strengthening in many countries (FAO 2017).

National forest inventories (NFI) are crucial for national forest monitoring (FAO 2015b) and are used to report to international frameworks, such as FAO's Forest Resources Assessment (FRA). Contributions to the FRA have increased, with 45 countries reporting forest estimates from NFIs in 2010 (FAO 2010) to 112 in 2015 (FAO 2015a). NFIs and national forest monitoring systems are continually evolving to improve precision and accuracy of estimates and, more recently, to consider policy needs (Kleinn 2017). Political and socioeconomic settings for policy decision-making about forests are complex and characterised by growing user demands and efforts to produce data that are not only technically reliable and cost-efficient but also relevant to and accessible by stakeholders (Arnold et al. 2014).

Bangladesh is a deltaic country with one of the largest population densities in the world (1253 people per $\left.\mathrm{km}^{2}\right)$. The current estimate of 163 million people is expected to grow to 192 million by 2050 (UNDESA 2019). Despite socio-economic and environmental challenges, in 2015, the country became a lower-middle income country and aspires to become an upper-middle income country by 2021 (GED 2018). However, the growing demands for food, energy, and timber put tremendous pressure on the remaining forests. While most of the deforestation happened in the semi-evergreen hill forests of the Chittagong region (Dhali 2008; Reddy et al. 2016), all forests, including the Sundarbans (the world's largest contiguous mangrove forest) and the coastal plantations, in particular the planted mangroves, are under pressure (Uddin et al. 2019). In addition, Bangladesh is one of the most vulnerable countries to climate change (Hasnat et al. 2018; Mojid 2020). Increasing income inequality and vulnerability of the poor to shocks such as those from natural disasters, and environmental degradation and unsustainable use of the remaining natural resources are major areas of concern. These may undermine its recent gains and future development trajectory.

Multiple forest inventories have been conducted in Bangladesh for different purposes and at various geographic scales. The impetus for conducting a forest inventory evolved over time, historically focusing on quantifying the timber resource, often for a specific purpose such as to service pulp mills (Forestal 1960), to more multipurpose inventories (Iftekhar and Saenger 2008). As the Government's focus changed to producing accurate forest information at the national scale, the first national forest and tree resource assessment was carried out in Bangladesh during 2005 to 2007 (FD, FAO, 2007). The 2007 inventory successfully provided national estimates of forest resources, however, its usefulness for monitoring tree and forest resources was limited because of the difficulty in re-locating the field inventory plots, and the limited documentation of the previous field data collection process (Costello et al. 2016). In addition, there was generally a lack of awareness of the data generated, limited access to the data, and insufficient 
information on key forest types such as Sal (Shorea robusta) and coastal forests. In summary, as in other countries, the usefulness of inventories prior to the current study in Bangladesh has been limited because of inconsistent methods, unclear data sharing structures, lack of skilled human resources, lack of access to technologies, and insufficient financial capacities. Yet, forestry information remains a high priority for Bangladesh as is recognized in key national plans and strategies such as SDG's (GED 2018), seventh 5 Year plan (GED 2015), Country Investment Plan for Environment, Forests and Climate Change sectors ( $G o B$ 2017a), the Reducing Emissions from Deforestation and Forest Degradation (REDD+) mechanism (MoEFCC 2018), the country's forest investment plan (MoEFCC 2018) and the Bangladesh Forestry Master plan 2017-2036 (FD 2016a). In the light of these plans, the Government is currently setting targets to enhance forest area, increase the area of treecovered land and increase the proportion of important sites for terrestrial and freshwater biodiversity by 2030 (GoB 2020a). Consequently, to meet the increasing need for tree and forest resource information, an institutionalised national forest inventory, which combines biophysical, land-use, and socio-economic data collected from the field and by remote sensing was envisioned in 2015 and implemented from 2016 to 2019. The aim of this article is to present the Bangladesh Forest Inventory, the centrepiece of the Forest Department's national forest monitoring system, including its design and operationalisation process and key results.

\section{Methods}

\section{Bangladesh Forest inventory design process}

The design of the Bangladesh Forest Inventory was prepared through a stepwise and consultative process. This included the development of a specific set of objectives and a process of identification of criteria, indicators and variable selection using the Design Tool for Inventory and Monitoring (Scott et al. 2009). Criteria and indicators are the means for monitoring the achievements or progress towards sustainable forest management (Julve Larrubia et al. 2017). Seven criteria and 47 indicators (Fig. 1) were identified for organising the BFI results along with other available data and information taking into consideration the need for the BFI to contribute to national and international reporting requirements as well as policy makers' data needs (GoB 2017b).

The wide ranging data needed for informing the criteria, indicators, and variables were collected across the country through sample plots for the biophysical data, sample households for the socio-economic data and using remote sensing for the land use and land cover mapping through collaborative efforts of different expert agencies (GoB 2020b).

\section{Integration}

An integrated approach considering both natural and social sciences (Zeng et al. 2015; Tewari 2016; Mensah and Casadevall 2019) is required for sustainable natural resource management through development of common indicators as they are interrelated and interdependent (De Lange et al. 2010). Three components (field inventory, remote sensing-based land cover analysis, and socio-economic survey) are integrated in the BFI to better inform decision-making to manage the interactions between people and natural resources for sustainable forest management. Particular attention was put into the sampling design of the socio-economic survey for the integration between the socio-economic and biophysical components.

\section{The biophysical NFI design process}

The design of the BFI is stratified random sampling with zones serving as strata, using quasi-systematic sampling within strata. The number of plots within each stratum was optimized to achieve minimum cost while also meeting national precision requirements for each of the key attributes of interest to be between $\pm 5 \%$ to $\pm 10 \%$ of the attribute mean at the $90 \%$ confidence level. This was achieved iteratively by using the Forest Resource Inventory, Edit and Design (FRIED) tool (Scott 1993) and following the process and inputs as described below.

\section{Stratification}

Five specific zones, which capture major differences in vegetation, soils, climate and land use, were used for stratification. The strata (or zones) afford the opportunity to use different sampling intensities to improve overall precision and to simplify estimation of change over time. The five zones are Sal (small forest areas dominated by Shorea robusta trees and mostly nonforest), Sundarban (dominated by mangrove tree species), Hill (hilly areas dominated by Dipterocarpus spp., Swietenia mahagoni, Tectona grandis, and others), Coastal (dominated by Sonneratia apetala, Avicennia officinalis, and Excoecaria agallocha), and Village (all areas not occupied by the other zones with no trees or mainly planted trees) (Fig. 2).

\section{Cost assessment}

Costs included on-plot costs (time and materials) and off-plot costs (travel, equipment, supervision and lab analysis). The estimated costs of each potential design combination were based on costs depending on the plot configuration, the number of plots, distances between plots, and accessibility within each zone.

The cost for transportation was calculated considering an average distance between field offices and any location in the zone, and the average transport cost within 


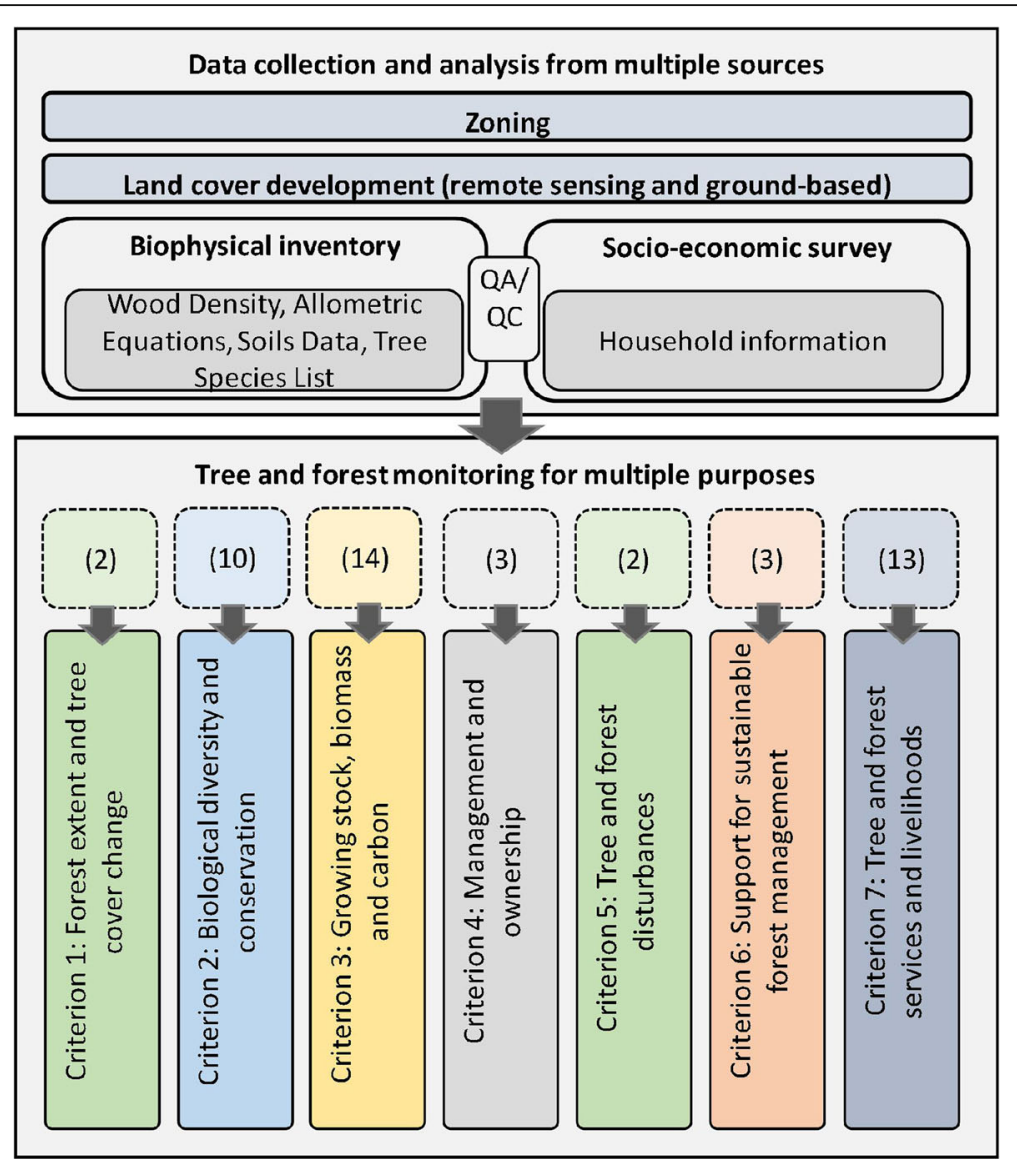

Fig. 1 Visualization of the relationships of data from multiple sources for multiple purposes in the BFI process. The numbering corresponds to the number of indicators in each criterion (modified from GoB, 2020a, b)

each zone (Fig. 3), and assuming that one plot is measured in 1 day and that the field team spent an average of 15 days in the field at a time for all zones except the coastal zones where field teams must go back to the duty station after each field visit.

\section{Optimization of sample size and plot configuration}

While there are linear, nonlinear and integer programming algorithms and software to do optimizations, these models do not accommodate well a mixture of models and integer and continuous design variables. The FRIED tool (Scott 1993) optimizes the process to select efficient plot configurations and sample sizes by minimizing the total inventory cost subject to fixed precision requirements (confidence interval and confidence limit) for key metrics (tree resource indicators) of interest. Since the target plot-related total costs were USD 2 million, adjustments were made as needed to the precision requirements. Combinations of plot configurations were formed by the number of subplot locations $(m)$, the average pairwise distance $(d)$ between subplot centres based on number, distance and spatial arrangement, such as L-shape or radiating from a single centre subplot location, the small tree subplot size $\left(z_{S}\right)$ and the large tree subplot size $\left(z_{L}\right)$. For each combination, the coefficient of variation (CV) was predicted for three key metrics (biomass, volume and number of trees). $\mathrm{CV}$ models were developed for three different land types, and two concentric plots designs for sampling small trees vs. large trees using data from previous forest inventories (FD, FAO, 2007; Donato and Iqbal. 2011) using Eq. (1):

$$
C V_{i}=b_{0} m^{b_{1}}(d+1)^{b_{2}} z_{S}^{b_{3}} z_{L}^{b_{4}}
$$

The sample size, $n$, for each metric $i$ is estimated using Eq. (2).

$$
n \geq \max \left[\left(\frac{t C V_{i}\left(m, d, z_{S}, z_{L}\right)}{\text { Error }_{i} \%}\right)^{2}\right]
$$

where, $n>2 ; n$ is the minimum required sample size across all metrics; Error ${ }_{i} \%$ is the confidence interval half width for the key metric $i$, e.g., $\pm 5 \% ; t$ is the Student's $t$ value based on the desired confidence level, e.g., 90\%; $C V_{i}$ is the percent coefficient of variation for key metric $i$ predicted using Eq. 1. 


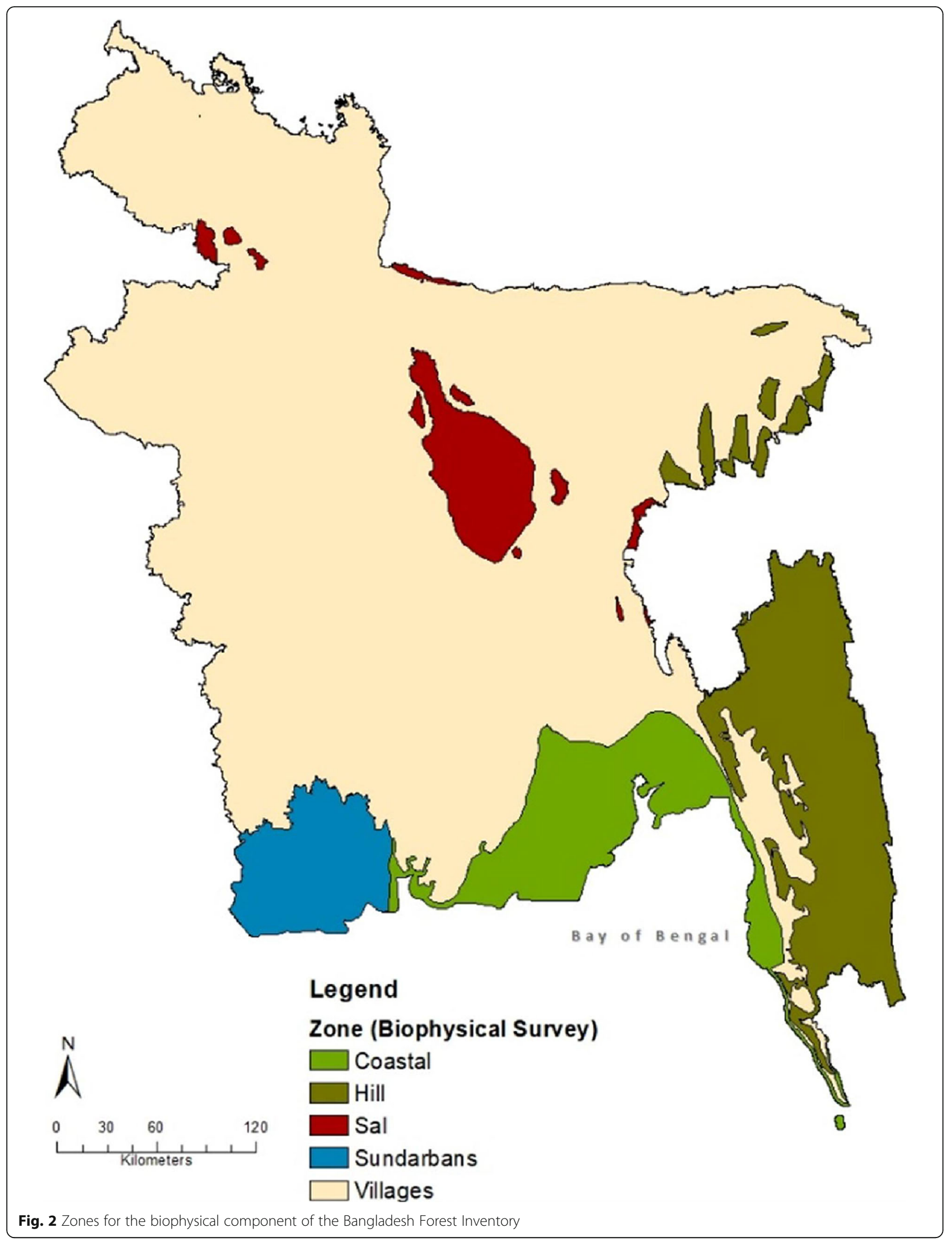




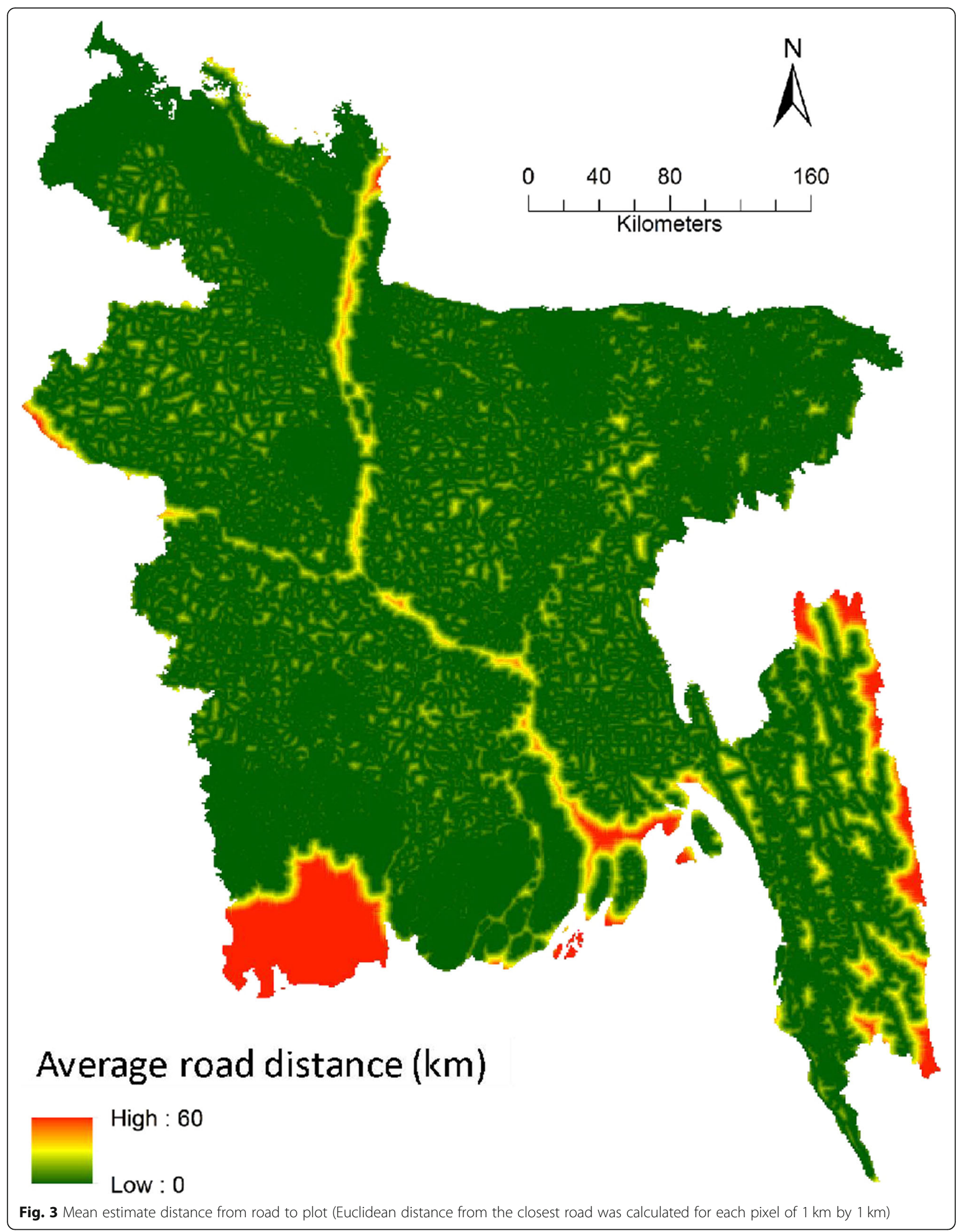


The optimization was performed by doing a grid search of different combinations of the plot configuration parameter $\left(m, d, z_{s}\right.$ and $\left.z_{L}\right)$ values, then evaluating the required sample size using Eq. 2, then estimating the cost of each combination to find the one which minimises cost.

The ultimate requirements are at the national level so the Neyman allocation (Cochran 1977) was used considering weights estimated as the proportion of the total area and variance in each zone using Eq. 3, so the larger and more variable zones were allocated more plots .

$$
n_{h}=n \frac{N_{h} S_{h}}{\sum N_{h} S_{h}}=n \frac{N_{h} \bar{x}_{h} C V_{h}}{\sum N_{h} \bar{x}_{h} C V_{h}}
$$

where, $n_{h}$ is the sample size in stratum (zone) $h ; N_{h}$ is the area of stratum $h ; S_{h}$ is the standard deviation of the metric in stratum $h ; C V_{h}$ is the coefficient of variation of the metric in stratum $h$; and $\bar{x}_{h}$ is the mean of the metric in stratum $h$.

Using the plot configuration parameters and the sample sizes by stratum, the total costs could be estimated. This process was repeated for thousands of different combinations until no further reduction in cost was found.

\section{Plot configuration}

Based on data from previous inventories and results after many iterations, the preferred plot configuration has 3 or 5 subplot locations, $38 \mathrm{~m}$ apart in cardinal directions (bearings 0, 90, 180 and 270 degrees). At each subplot location three concentric circular subplots are observed for trees, each with a different radius $(19,8$ and $2.5 \mathrm{~m}$ ) corresponding to different tree diameter thresholds $(\geq$ $30 \mathrm{~cm} \mathrm{DBH}, \mathrm{DBH} \geq 10 \mathrm{~cm}$ to $<30 \mathrm{~cm}, \mathrm{DBH} \geq 2 \mathrm{~cm}$ to $<$ $10 \mathrm{~cm}$ ) for all zones. The smallest subplot for regeneration is offset $5 \mathrm{~m}$ to the east to avoid trampling. Four down woody transects and a soil sample are observed at each subplot location as well (Fig. 4). Here, the plot refers to having five subplot locations (each with three subplots) in the Sal, Village, Hill and Coastal areas or three subplot locations for the Sundarban area. The adjustment to three subplot locations in the Sundarban area was made to ensure that field data collection could be carried out in a single day due to the complicated logistical arrangement to reach each parcel in these remote areas (Fig. 4b).

\section{Plot selection}

As mentioned, the BFI uses stratified random sampling with zones serving as strata, using quasi-systematic sampling within strata, and the strata sample sizes were selected using Neyman allocation to maximize the precision across strata (FD 2016b). To determine the plot locations, a hexagonal grid reflecting the desired stratum sample size was constructed as the sampling frame, such that the hexagon area was the stratum area divided by the stratum sample size. One plot from the grid was randomly selected in each hexagonal grid cell (Fig. 5). If the selected location fell outside the stratum, then no plot in that zone was selected for that hexagon which helped ensure that the desired sample size was achieved (forcing one in each hexagon would not). Accordingly, the number of expected plots to be visited in each stratum was obtained (Table 1).

\section{Data collection}

The land feature related information, i.e. land cover, canopy cover, vegetation type, crown density, was collected at the plot level. At the subplot level, data for tree measurements (live and dead), down woody material, litter, and soil samples were collected. All live and dead standing trees and stumps $\geq 30 \mathrm{~cm} \mathrm{DBH}$ were measured within the largest subplot; all live and dead standing trees and stumps with $\mathrm{DBH} \geq 10 \mathrm{~cm}$ to $<30 \mathrm{~cm}$ and bamboo clumps were measured in the intermediate subplot; all live, dead saplings and stumps with $\mathrm{DBH} \geq 2 \mathrm{~cm}$ to $<10 \mathrm{~cm}$ of two non-tree species (Nypa fruticans and Cerops decandra) and all tree seedlings for regeneration

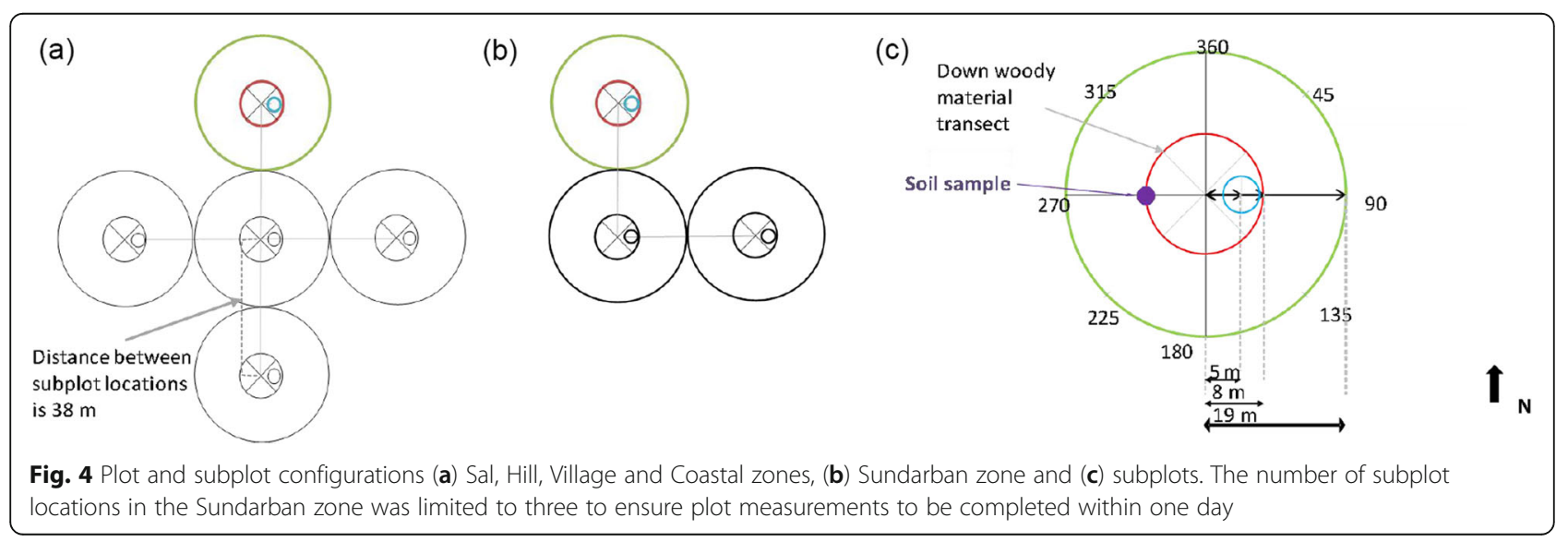



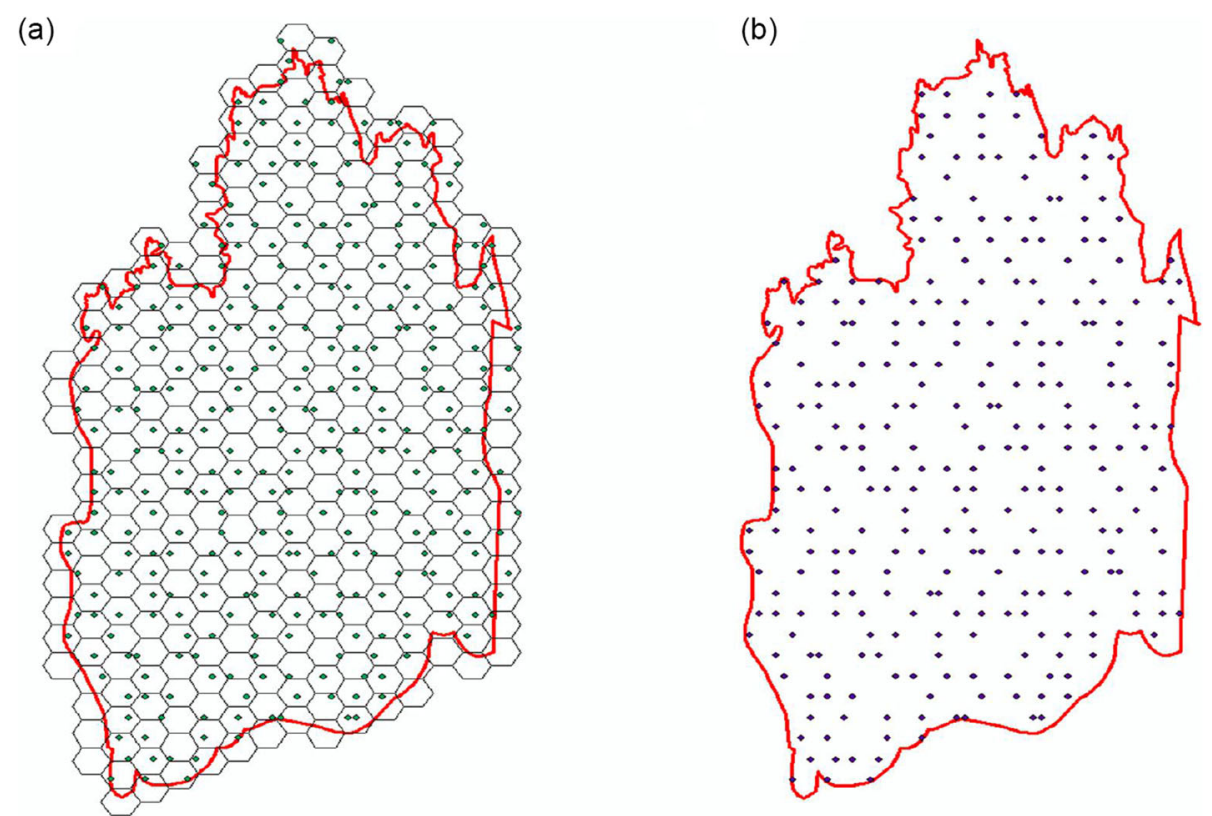

Fig. 5 Selection of plots by hexagonal grid in the Sundarban zone (a) random selection of plot location for each hexagon (including outside the boundaries) and (b) selected plot locations within the zone

estimation $(\mathrm{DBH}<2 \mathrm{~cm})$ were measured in the smallest subplot. Down Woody Material was measured on four transects per subplot location, each transect starting at the subplot centre and extending $8 \mathrm{~m}$ at $45^{\circ}, 135^{\circ}, 225^{\circ}$ and $315^{\circ}$. Small $(<1 \mathrm{~cm})$, medium $(1-3 \mathrm{~cm})$ and large $(3-8 \mathrm{~cm})$ pieces were counted and the diameters of coarse pieces intercepting the transect were measured. Litter (collected within $1-\mathrm{m}^{2}$ frame) and soil samples (at $0-15 \mathrm{~cm}$ and $15-$ $30 \mathrm{~cm}$ soil depths in all zones and $30-100 \mathrm{~cm}$ soil depth in the Sundarban zone) were collected in the three subplot locations at eight meters and $270^{\circ}$ from the subplot centre. Laboratory analyses were conducted to measure litter carbon content, the soil bulk density and organic carbon content (by loss on ignition method). Moreover, additional information was collected at the plot and subplot level such as land management, ownership, disturbances. Detailed information about the data collection process is provided in the field inventory protocol (FD 2017a).

\section{The socio-economic design}

\section{Sampling framework}

The socio-economic survey used stratified sampling with two-stage sampling within strata (GoB 2017c). The strata were defined first by the five zones of the socioeconomic component and were identical to the biophysical component except for the Sundarban zone where no people live (Fig. 6). Each stratum was subdivided into four sub-strata, that were defined by classifying all unions within each stratum into quartiles of the variable Household Tree Availability, which is estimated as percent tree cover per household (\% $\left.\mathrm{TC} \cdot \mathrm{HH}^{-1}\right)$ using Eq. 4. The definition of sub-strata was based on the assumption that tree and forest ecosystem services to households is related to tree cover per household, which is a proxy for the quantity of tree and forest resources available. Thus, the total number of sub-strata is 20 (4 classes within 5 zones). To have an equal distribution of unions

Table 1 Number of expected and visited plots and subplot and sampling intensity by zone

\begin{tabular}{lllllll}
\hline Zone & Land area (ha) & $\begin{array}{l}\text { Expected number } \\
\text { of plots }\end{array}$ & $\begin{array}{l}\text { Expected number } \\
\text { of subplots }\end{array}$ & $\begin{array}{l}\text { Number of } \\
\text { visited plots }\end{array}$ & $\begin{array}{l}\text { Number of } \\
\text { visited subplots }\end{array}$ & $\begin{array}{l}\text { Expected sampling } \\
\text { intensity (ha per plot) }\end{array}$ \\
\hline Hill & $1,716,149$ & 428 & 2140 & 376 & 1664 & 4010 \\
Sal & 534,430 & 145 & 725 & 142 & 619 & 3686 \\
Sundarban & 632,680 & 173 & 519 & 173 & 467 & 3657 \\
Coastal & 986,618 & 113 & 565 & 109 & 506 & 8731 \\
Villages & $10,887,123$ & 998 & 4990 & 981 & 4469 & 10,909 \\
Total & $14,757,000$ & 1858 & 8713 & 1781 & 7725 & 7942 \\
\hline
\end{tabular}

${ }^{a}$ The number of visited plots reflects the fact that the crews were unable to safely access 77 plots 


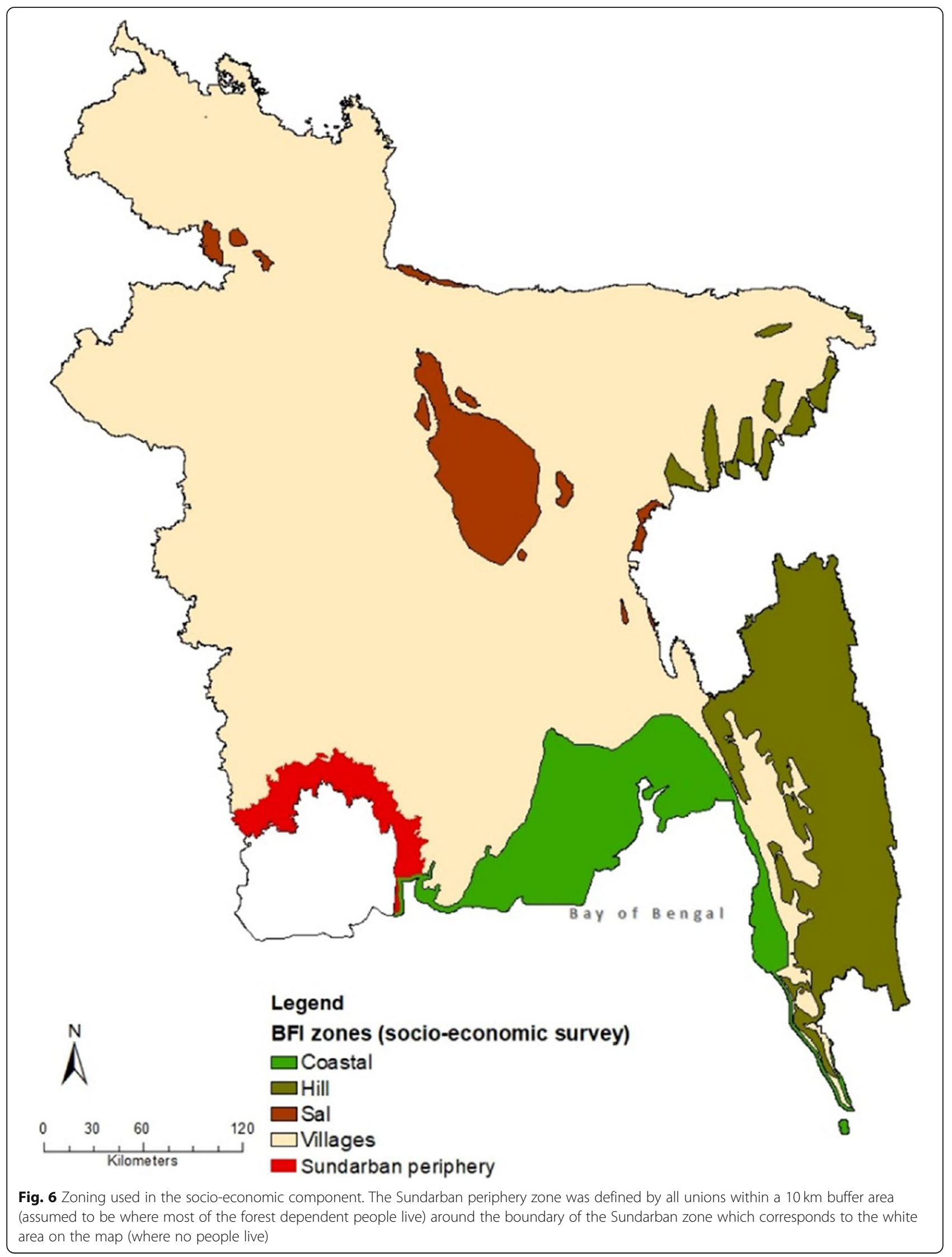


(primary sampling units) in each sub-stratum, 16 unions were randomly sampled from each sub-stratum, which results in 64 unions selected in each stratum and 320 at the national level (GoB 2017c). Within each selected union, a random sample of 20 households was selected for interview as the secondary sampling units.

$$
\text { Household Tree Availability }=\frac{\left(\frac{\text { TCarea }}{\text { Union area }}\right)}{\text { Number } \mathrm{HH}^{\prime} \mathrm{s}}=\frac{\% T C}{H H}
$$

where, $T C$ is the tree cover estimated from remotely sensed Landsat data from 2014 (Potapov et al. 2017), and $\mathrm{HH}$ is the number of households from the 'Population and Household Census - 2011' dataset (BBS 2015).

\section{Sampling design}

The estimation of the optimal sample size in complex surveys, such as the present one, is not a trivial exercise. When information on more than one item must be collected, it is necessary to focus on the item which is considered as the most relevant to the survey. One of the most relevant outcomes of the survey is the number of people depending on forest resources in each zone (stratum). Each substratum is designed to be homogeneous based on the variable (tree cover/number of households/area) considered and the number of unions selected was equal in each substratum.

\section{Sample size}

The sample size was calculated for each zone using Eq. 5 (Cochran 1977) considering an uncertainty in the number of forest-dependent people of $\pm 5 \%$ (at a $95 \%$ confidence level) for each zone.

$$
n_{0}=\frac{t^{2} p q}{e^{2}}
$$

where, $n_{0}=$ the sample size; $p$ the estimated proportion of an attribute that is present in the population; and $q$ is $1-p$ and $e$ the margin of error to be attained (here \pm $0.05)$. Setting the value of $p$ to 0.5 results in the largest variance for a proportion, thus yielding a large (conservative) sample size. By using Eq. 5, the resulting sample size was 384. That assumes a simple random sample of households. The sample size was increased by $10 \%$ to compensate for non-response. In addition, the design effect to account for clustering of households within unions was chosen as 3 which was a conservative choice. The total number of households to be surveyed in each zone was $1268(384 \times 3 \times 1.1)$, which corresponds to a total of 6340 $(1268 \times 5)$ and $0.02 \%$ of households at a national level.

\section{Sample selection}

Because a list of enumeration areas from the agricultural census was not available and the agricultural census does not provide information related to tree and forest dependency, households were selected within the selected unions (Fig. 7) by randomly generating five GPS points within the "rural settlement" and "built-up areas" land cover classes of the 2015 national land cover map. Interviewers then navigated to the five GPS points and chose the nearest four households to interview so that 20 households were visited in each union. A total of 6400 households from 320 unions were surveyed (20 substrata $\times 16$ unions $\times 20$ households $=6400$ total households) . Of the respondents, $53 \%$ were female and $47 \%$ were male. The 2015 land cover map was used by enumerators to ask respondents from which land cover certain primary products were collected (FD 2017a).

\section{Socio-economic survey}

A structured questionnaire was prepared considering the identified criteria and indicators, an optimal size of the questionnaire, and identifying target groups for the Focus Group Discussions (FGDs). The questionnaire was tested to ensure that the questions were clear and then used for interviewing the selected households (Rahman and Jashimuddin 2017).

\section{Focus group discussions}

In addition to the household survey, one hundred FGDs were carried out across the whole country (20 in each zone) involving important stakeholders (e.g., forest resource users) that were identified from the household survey to collect information related to trends of land use, access to services, tree and forest products prices based on market value and benefits from tree and forest resources.

\section{The national land cover map}

A national land cover representation system (NLRS) for Bangladesh (GoB 2017d) using the Land Cover Classification System (Di Gregorio and Leonardi 2016) and following the Land Cover Meta Language (LCML) ISO 19144 (ISO 2012) was prepared as the result of several processes of data collection, translation, gap identification and analysis of existing land cover/use mapping processes.

The legends of three existing national land cover/use maps were collected, documented and translated using the Land Cover Classification System (LCCS v3) - an implementation tool of ISO standard (ISO 19144-2) LCML (Di Gregorio and Leonardi 2016). This step identified the gaps in existing legends and assisted the interpretation of land feature classes considering the objectives of the institutions responsible for land cover map development. In parallel, field data were collected, using Open Foris Collect (Costello and Piazza 2015), from 1144 locations across the country to characterize the classes of the NLRS (BSGI FD, 2016). 


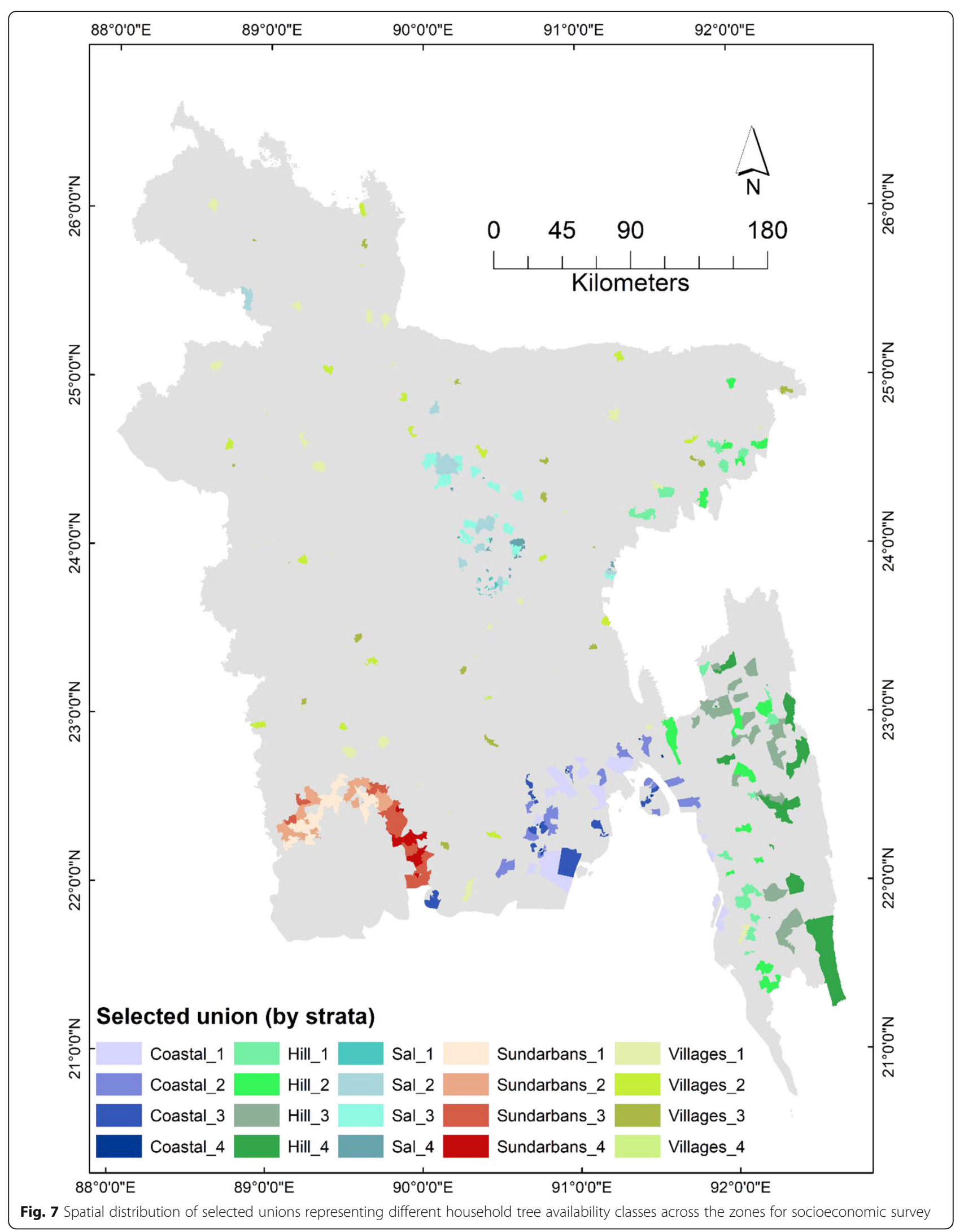


From the NLRS, the initial legend classes for land cover map 2015 were derived during a national workshop with experts from different organizations working in relevant fields (Udita et al. 2016). These initial classes were further refined during map development process to develop the final legend. Some of the classes were extended from the NLRS (e.g., bamboo forest, rubber plantation, etc.), while some other classes were merged (e.g., short and long rotation plantation into forest plantation) when differences among these classes were not discernible from the available satellite images by visual interpretation. The final land cover map has 33 classes.

For the development of land cover map 2015 (Fig. 8), multi-spectral ortho (Level 3) SPOT6/7 four band images of $6-\mathrm{m}$ spatial resolution with maximum $10 \%$ cloud coverage were primarily used for the whole country. An Object-Based Image Analysis approach (i.e., multi resolution segmentation algorithm (Baatz and Schäpe 2000)) was adopted to create image objects using the green, red and near-infrared bands of SPOT imagery. Meaningful image segments (Castilla and Hay 2008) were directly assigned with land cover code by visual interpretation. Image segments not corresponding well to geo-objects were manually edited (i.e., manual digitization by visual interpretation of satellite image) before assigning an appropriate land cover code. Seasonal variations in land and water features are common in Bangladesh. Landsat 8 and Sentinel 2 images from different seasons were taken into consideration in visually interpreting areas having a seasonal variation (especially agricultural classes).

Quality checking was an integral part of the whole production chain and was completed using multiple approaches including a spatial topology check, an attribute check, a consistency check, expert judgment and field validation. The accuracy assessment analysis of the land cover map was performed through visual interpretation of fine resolution imagery (pseudo-ground truth validation technique), with stratified random sampling by district and by land cover class. The most commonly used measures of accuracy (i.e., overall accuracy, user's accuracy, producer's accuracy) were estimated following the approach suggested in Olofsson et al. (2013) and presented in Jalal et al. (2019). The overall accuracy, through visual interpretation, was estimated at $89 \%$. User's accuracy ranged from $20 \%$ to $99 \%$ while producer's accuracy ranged from $13 \%$ to $100 \%$. The detailed methodological process and results (including the accuracy, uncertainty and adjusted area estimates) of land cover 2015 are presented in Jalal et al. (2019).

\section{Operationalization}

In total, 51 trainings, 10 workshops, and 14 consultations involving 1206 people were conducted to provide all technical expertise to the different teams for the biophysical, socio-economic and remote sensing components of the BFI. The three components were planned to be implemented within a four-year period (1 year for enhancing technical capacity, 2 years for the field data collection and 1 year for data analysis and sharing the results). The field data collection was supervised by a Conservator of Forests from the Forest Department, while local Conservators of Forests supervised the field implementation in each district.

Regarding the biophysical component (FD 2016b), one specific working group constituted by the Chief Conservator of Forests was established to oversee its implementation. The measurements on field plots were performed by 13 field inventory teams of seven members. Local people were engaged as much as possible in the composition of the field team or as guides. Local FD staff helped by providing information about access conditions to the plot and recruiting local people with required local knowledge. Field teams were trained using a manual developed by FAO, SilvaCarbon and staff from universities and two research organisations (FD 2017a). Field work preparation involved maps, digital field forms, equipment and other logistics. Quality control was achieved through hot and cold checks on 3\% and 7\% of the plots respectively by four Quality Assurance and Quality Check (QA/QC) teams composed of FD and the University Faculty members (FD 2016c).

The data were collected in the field using the Open Foris Collect Mobile app (FAO 2018a) installed on tablets. The data were exported to an online data repository as '.collect-data' files and then imported to the Open Foris desktop version regularly for conversion to other data formats (e.g. .csv, .xml). This ensured a more efficient and cost-effective field data collection and facilitated quick and ready access and validation of the data by Forest Department. Validation rules included data type validation (verifies that the data entered are consistent with the expected primitive data type), range checks (verifies that the entered value falls within an accepted value range), checks for missing records (flags missing data, miscoded data values appearing to be outliers and other issues), and cross checks (whether the data entered in different fields is consistent with other fields based on a set of underlying assumptions). Field data collection concluded by visiting 1781 out of 1858 plots (1480 accessible, 301 partially accessible), or $96 \%$ of the total. Of those plots which were not measured at all, 42 were inaccessible plots $(2.3 \%)$ and 35 were not measured for other reasons $(1.9 \%)$. In the case of inaccessible plots, a visit was attempted but tree measurements were not possible in any subplot, most commonly due to the plot centre falling inside hazardous conditions such as steep slopes $(52 \%)$, water $(33 \%)$, or other reasons such as denied access, restricted areas, or wall or building (15\%). 


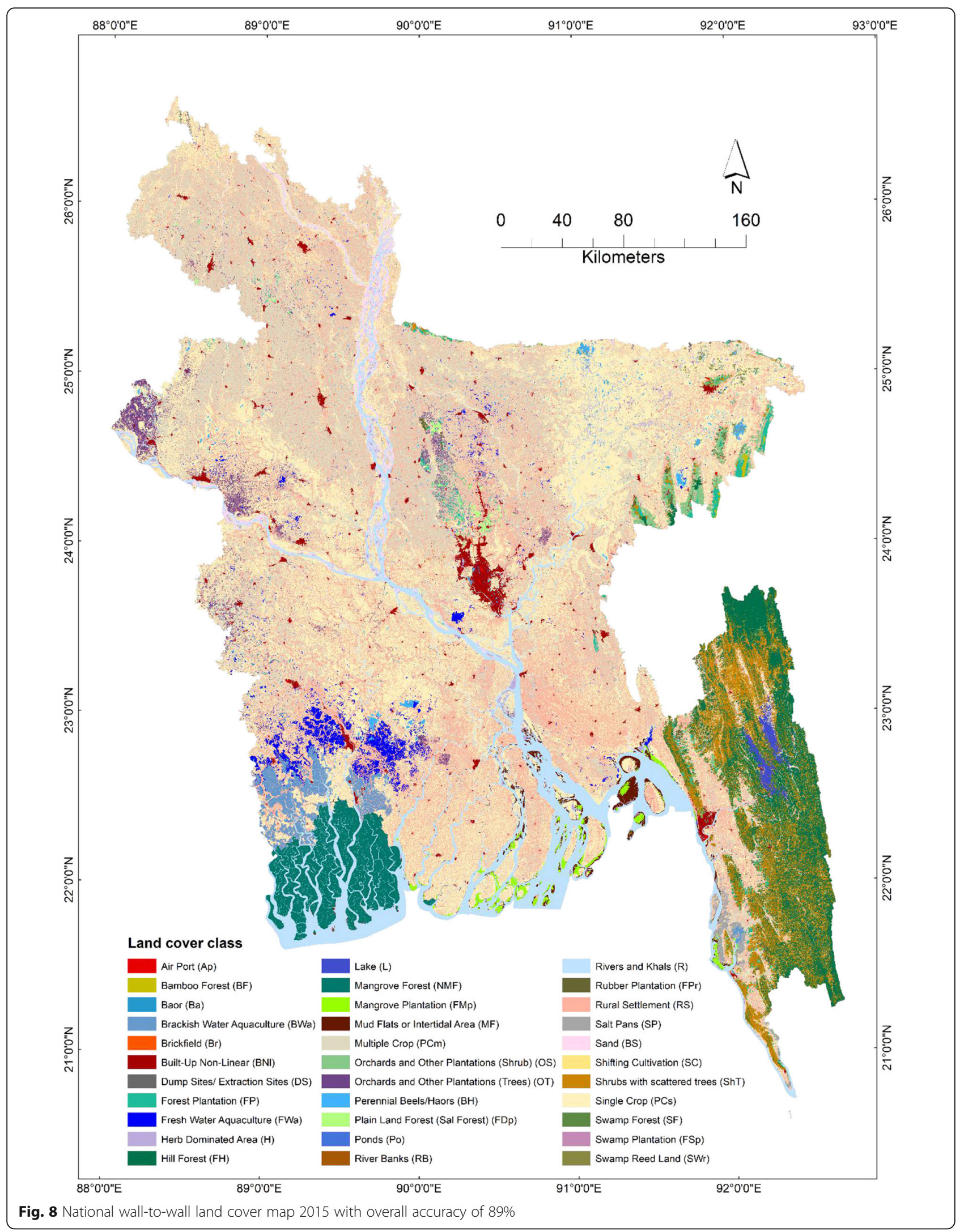


The socio-economic component (GoB 2017c) was overseen by a separate working group from relevant universities, Government and non-government organisations. It was implemented by a contracted entity experienced with socio-economic data collection. The data were collected by five enumerator teams with five members in each team which followed the manual for the socio-economic component (FD 2017b). For verification of household interviews and ensuring consistent field data collection, a quality assurance and quality control (FD 2016c) was conducted in 4\% interviewed households (254 hot checks, 13 cold checks).

The preparation of the national land representation system (GoB 2017d) and the land cover map involved 13 national entities. In addition, agreements were signed with other organisations for the preparation of, for example, the land representation system (Soil Resource Development Institute, Bangladesh Society of Geo-Informatics and the Centre for Environmental and Geographic Information Services), allometric models (Khulna University, Bangladesh Forest Research Institute), soil analysis and archiving (Soil Resource Development Institute, Dhaka and Khulna University), the development of the Bangladesh Forest Information System (Bangladesh Computer Council), and the tree species list (Bangladesh National Herbarium). The collected data were documented, archived, and shared with stakeholders through the Bangladesh Forest Information System (FD 2019) and the main results are presented in the upcoming BFI report (GoB, 2019).

\section{Allometric models}

A national database of allometric models was prepared to identify gaps and needs for further development (Hossain and Siddique 2016). Among the 517 models, only 189 species-specific models belonging to 35 tree species (including several models for the same species with differences such as sample size, diameter range, author, year) were identified as valid in a country with rich biodiversity which indicates a great dearth of siteand species-specific allometric models (Hossain 2016). Based on this review, new allometric models were developed to fill needs at both species and zone levels through extensive field tree data collection in all five zones (Hossain and Siddique 2016). A decision tree for selecting the most appropriate allometric models was developed (Hossain et al. 2019).

\section{Data analysis}

All the estimation procedures of the BFI indicators were documented to ensure transparency, sustainability and future improvement (Hossain et al. 2019). The data collected were archived into a mass storage for backup. MS Access and R-scripts were used for updating the database regularly with predefined queries. For data cleaning and cold checking individual plot reports were prepared as .pdf from MS Access. Data cleaning was done through multiple procedures including within the Open Foris platform, manual cleaning based on the errors identified in the plot report and identifying inconsistencies or outliers through running customized Rscripts.

After data cleaning, customized R-scripts (supplementary information 1) were used for the estimation and are based on the assumptions for stratified random sampling (Hossain et al. 2019). The ratio-to-size sample-based estimator (Thompson 2012; Korhonen and Salmensuu 2014; Scott 2018) combined with stratified random sampling estimators were used to estimate the means, totals and variances for national and zone level statistics using the equations in Table S2.1 (e.g. stem density, basal area, volume, biomass and carbon stock). One of the reasons for choosing the ratio-to-size estimator is because of the ability to include plots which are incompletely measured (i.e. when some subplots within a plot were inaccessible). The estimator was also used for estimating disaggregated statistics based on additional domains as per stakeholder requirements (e.g. land cover, forest / other land, or administrative boundaries).

For estimation of land cover area, the subplot boundaries were overlaid with the land cover map to assign land cover classes and areas within each subplot. The decision to use the land cover information directly from the map avoids possible inconsistency and errors arising from determination of land cover information from field (e.g. land cover boundary delineation within a subplot, number of land covers, etc.). Visual interpretation of fine resolution imagery revealed that the map more consistently characterised the land cover than the field classification approach (Figs. S3.1, S3.2 and S3.3). Differential global positioning system coordinates were available for most of the plots to reduce errors related to the misalignment of the map and subplots.

The wall-to-wall Landsat based tree cover extent and change maps, developed by the Resources Information Management System unit of FD and the University of Maryland (Potapov et al. 2017), have been integrated with land cover 2015 data. At the scale of the polygons of the land cover map 2015, zonal statistics of the 20002014 tree cover data were estimated. This resulted in each polygon of the land cover map containing the number of pixels with tree cover in 2000, and the number of pixels with tree cover gains and the number of pixels with tree cover loss for each year between 2000 and 2014. Based on this, tree cover percentage within each land cover class was estimated for 2000 and 2015 (assuming 2014 tree cover), and changes in percentage tree cover were also estimated. 
Stratum-specific mean values of carbon density were assigned by land cover classes for the preparation of the map of carbon density (Fig. 9). The carbon density with standard errors by stratum and land cover classes were provided in Table S2.2.

\section{Key results}

\section{Criterion 1 - trees and forest extent}

Forest land cover area derived from the land cover map and the stratified area estimates obtained after the accuracy assessment for 2015 are provided in Table 2. Based on the FRA definition of forest cover (FAO 2018b), forest cover in Bangladesh was $1,884,019$ ha, or $12.8 \%$ of the total country area. This amounts to 11.7 ha per 1000 people. When only terrestrial land area was considered (i.e. excluding river area), the forest cover was $14.1 \%$. Hill Forest was the largest forest type by area (4.6\% of the country area) followed by Shrubs with Scattered Trees (4.2\%) and Mangrove Forest (2.7\%). Land covered by Permanent Crops accounted for half of the country's area and although these areas are primarily used for agriculture, they still had a mean tree cover of approximately $7 \%$ (GoB 2020b). Nationally, there was a net decrease in tree cover of 3.4\% from 2000 to 2015 (GoB 2020b).

\section{Criterion 2 - biological diversity and conservation}

A total of 392 species was recorded in the biophysical survey with the largest number of species in the Hill zone (primarily Hill Forest) followed by the Village zone (primarily Rural Settlement) (Table 3). The Hill zone is composed mainly of naturally regenerated forest whereas trees in the Village zone are mostly planted and are often fruit trees. Biological diversity in terms of number of tree species per land cover area is richest in the Hill Forest and Rural Settlements, with each of these zones having more than 232 different species. However, 63\% of individual trees in the Rural Settlement are introduced species, compared to only $33 \%$ in the Hill Forest. The inventory recorded the largest number of tree species in the Hill zone though the basal area was only $29 \%$ of the total basal area of Sundarban zone (Table 3 and Table 4). This indicates that the more intense planting activities in the Hill zone may at least be partially responsible for the richer biological diversity. At least two species in the Hill zone were endangered or critically endangered (A. agallocha and $A$. scaphula) according to the IUCN Red List.

\section{Criterion 3 - Forest growing stock, biomass and carbon}

The Sundarban being the zone with the largest densities of stems, basal area, gross volume, biomass and carbon (Table 4). C. decandra, E. agallocha, and H. fomes are the three dominant species in terms of stem density across the country, though they almost exclusively occur in the Sundarban zone. As a single land cover class,
Rural Settlements is the largest source of the national growing stock volume contributing $50 \%$ of the total growing stock which is $270 \%$ larger than the volume in Forest area.

Trees outside forest (i.e. trees in other land), which include rural settlement areas, contained $66 \%$ of the total biomass whereas the greatest biomass density occurred in the mangrove forest. One mangrove species (Heritiera fomes), one fruit species (Mangifera indica), and one introduced species (Swietenia mahagoni) make up the top three species by biomass in the country, and 19\% of the total biomass. Biomass that is usable as fuelwood (i.e. coarse woody debris, fine woody debris, and litter) was largest in the Hill Forest (3408 tons biomass, or 33\% of the total), but substantial amounts were also present in Rural Settlements (2587 tons, or 25\%).

The total terrestrial carbon stock (aboveground, belowground, dead wood, litter and soil) was estimated to be 1275.6 million tons. Carbon stock density was largest in the Sundarbans zone compared to other zones, primarily due to its large aboveground, belowground and soil carbon stocks (Fig. 9, Table S2.2). Most of the country's carbon stock is held in soils to $30-\mathrm{cm}$ depth $(80.5 \%)$, followed by aboveground (15\%), belowground (4\%), dead wood $(0.5 \%)$, and litter $(0.1 \%)$ biomass.

\section{Criterion 4 - Forest management and ownership}

Tree and forest management is being conducted on an estimated 3.1 million ha of land covering $23.2 \%$ of the total area. Forest land ownership is still being delineated in Bangladesh. Nonetheless, the BFI is a sample of the total land area and may be used to estimate proportions of ownership types. Almost $9.4 \%$ of the total land was owned by the FD, containing $24.5 \%$ of the country's total aboveground carbon stock. Several plantation management types (block, woodlot, coastal, rubber or strip) made up $48 \%$ of the managed land, whereas the rest of the managed land was mostly homestead forest, agroforestry, orchards or tea gardens. Most of the households collected their tree and forest products from privately owned lands chiefly for energy (41\% of total households), materials $(8 \%)$, and food (7\%).

\section{Criterion 5 - tree and forest disturbances}

About 32\% of the Forest area experiences natural disturbances, with landslides, erosion, and cyclones as the most common types. In contrast, in trees outside forest, the most common disturbance was waterlogging. Disturbance was also assessed through household interviews, where respondents overwhelmingly identified cyclones and infrastructure development as major disturbance types. When asked more specifically about the reasons for tree cover loss, the respondents mostly identified overharvesting and tree removals for construction. 


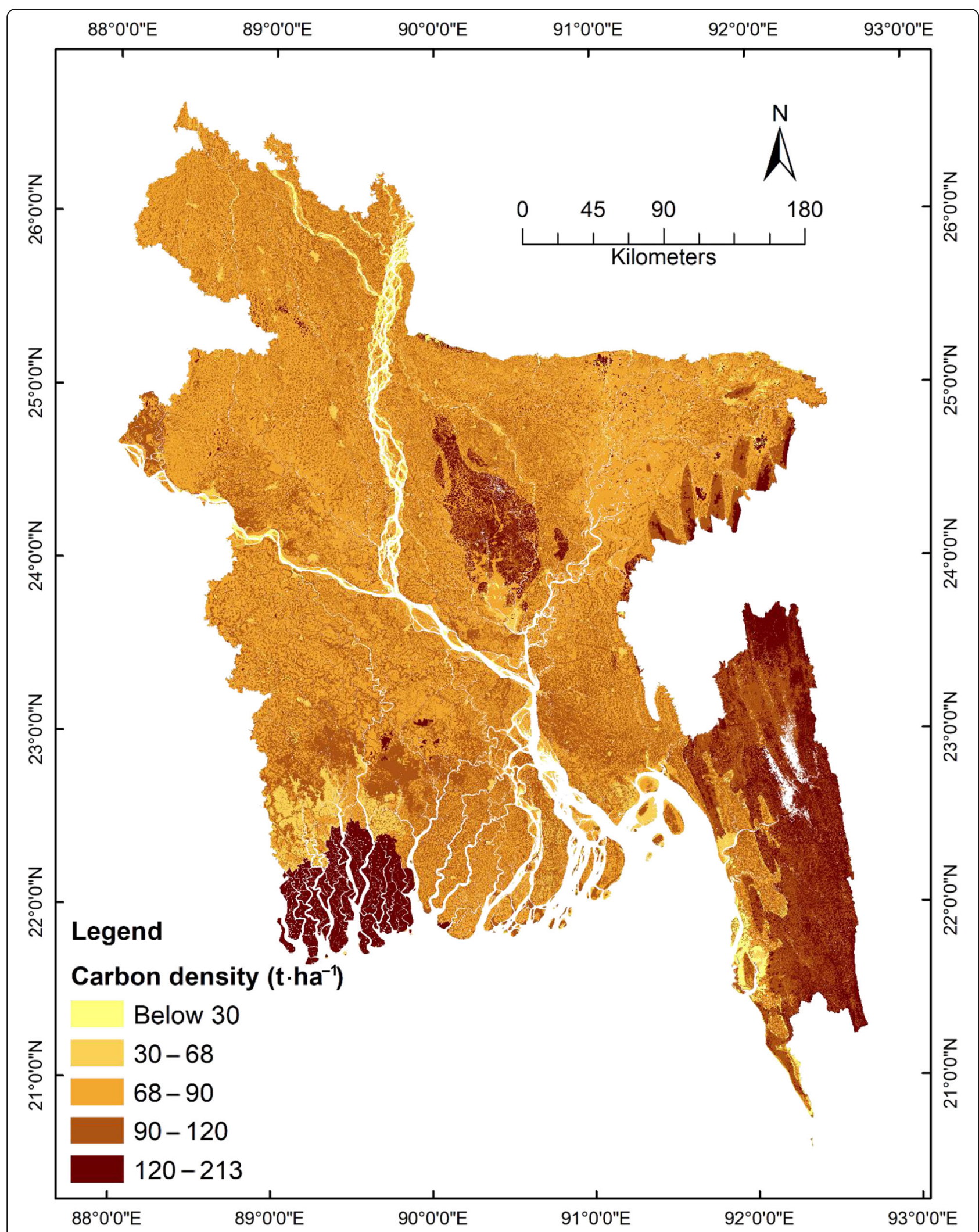

Fig. 9 Spatial distribution of the carbon stock density estimates across the country in 2015 using carbon stock densities available in Table S2.2 
Table 2 Land area of forest classes, their proportion of total country area, stratified area estimates and standard error estimates

\begin{tabular}{|c|c|c|c|c|c|c|}
\hline \multirow[t]{2}{*}{ Forest land cover classes } & \multicolumn{2}{|l|}{ Map area } & \multicolumn{2}{|c|}{ Stratified estimates } & \multicolumn{2}{|c|}{ Standard error } \\
\hline & (ha) & Proportion of total country (\%) & (ha) & Proportion of total country (\%) & (ha) & (\%) \\
\hline Hill Forest & 683,852 & 4.63 & 894,204 & 6.06 & 22,268 & 2.5 \\
\hline Shrubs with scattered trees & 614,537 & 4.16 & 354,757 & 2.40 & 22,093 & 6.2 \\
\hline Mangrove Forest & 402,185 & 2.73 & 419,149 & 2.84 & 4518 & 1.1 \\
\hline Forest Plantation & 79,299 & 0.54 & 68,090 & 0.46 & 7622 & 11.2 \\
\hline Mangrove Plantation & 55,089 & 0.37 & 30,723 & 0.21 & 3831 & 12.5 \\
\hline Rubber Plantation & 23,684 & 0.16 & 37,357 & 0.25 & 5789 & 15.5 \\
\hline Plain Land Forest (Sal Forest) & 18,918 & 0.13 & 17,606 & 0.12 & 2744 & 15.6 \\
\hline Bamboo Forest & 5686 & 0.04 & 6246 & 0.04 & 1633 & 26.2 \\
\hline Swamp Plantation & 628 & 0.004 & 302 & 0.00 & 45 & 14.9 \\
\hline Swamp Forest & 140 & 0.001 & 431 & 0.00 & 269 & 62.4 \\
\hline Forest area & $1,884,019$ & 12.77 & $1,828,865$ & 12.39 & 33,480 & 1.8 \\
\hline
\end{tabular}

Criterion 6 - support for sustainable forest management The socio-economic survey revealed that few respondents (1.3\%) received support for sustainable tree and forest management from any organization. Those who reported receiving support, identified support mostly in the form of free seedlings and trainings on tree planting. People usually purchase seedlings and planting materials from a local market; but in some cases, they receive free seedlings from the Forest Department along with other organizations. Nationally, 43\% of the households purchased their own seedlings over the past year (2017 to 2018) and spent an average of 1015 BDT (12 USD, 1 $\mathrm{USD}=84.36 \mathrm{BDT}$ ) per year to purchase seedlings.

\section{Criterion 7 - trees and forest services and livelihoods}

The socio-economic survey revealed that trees and forests are a rich source of materials, energy, nutrition, and income for most households. An estimated $64 \%$ of the total population was involved in collecting primary tree and forest products. The total estimated value of the primary tree and forest products collected was $3.07 \%$ of the 2017-2018 national Gross Domestic Product (GDP) measured in current price. The value of collected products to the household was on average BDT 19518 per year (USD 231.4 per year), mostly contributed in the form of fruit (47\%) and energy (40\%).

Trees outside forest supply most of the country's primary tree and forest products. An exception is in the Hill zone, where about $70 \%$ of the timber, bamboo, firewood, and leaves, and almost half of the fruit are supplied from Forest areas near the households.

The total value of products used for cooking and heating was 202,927 million BDT per year (USD 2405.5 million per year). The annual value of these products to households in the Hill zone was nearly $400 \%$ of the national average value (BDT 24476 v. $6138 \mathrm{HH}^{-1}$.year ${ }^{-1}$, USD 290 v. $73 \mathrm{HH}^{-1}$. year $^{-1}$, respectively). The average cost of buying forest products for cooking and heating purposes was BDT $2554 \mathrm{HH}^{-1}$. year $^{-1}$ (USD $30 \mathrm{HH}^{-1}$.year ${ }^{-1}$ ) nationally.

In terms of income, a household in Bangladesh annually earns BDT 9160 (USD 108) from selling primary tree and forest products which contributed to $1.29 \%$ of the $2017-$ 2018 national Gross National Income (GNI) measured in current market price. Households belonging to larger

Table 3 Tree and sapling species, families, species richness and threatened species by zone (stratum). The species richness index is calculated based on Margalef (1958)

\begin{tabular}{|c|c|c|c|c|c|c|c|c|}
\hline \multirow[t]{3}{*}{ Zone } & \multicolumn{2}{|c|}{ Number of species } & \multicolumn{2}{|c|}{ Number of families } & \multirow{3}{*}{$\begin{array}{l}\text { Species } \\
\text { richness } \\
\text { index }\end{array}$} & \multirow{3}{*}{$\begin{array}{l}\text { Total } \\
\text { number of } \\
\text { threatened } \\
\text { species }\end{array}$} & \multirow{2}{*}{\multicolumn{2}{|c|}{$\begin{array}{l}\text { Density of threatened } \\
\text { tree species }\end{array}$}} \\
\hline & Trees \& & RegeneratingSpecies & Trees \& & RegeneratingSpecies & & & & \\
\hline & $\begin{array}{l}\text { saplings } \\
\text { ( } \geq 2 \mathrm{~cm} \\
\mathrm{DBH})\end{array}$ & & $\begin{array}{l}\text { saplings } \\
\text { ( } \geq 2 \mathrm{~cm} \\
\mathrm{DBH} \text { ) }\end{array}$ & & & & $\left(\right.$ Stem $\left.^{\prime} \mathrm{ha}^{-1}\right)$ & $\mathrm{SE}( \pm \%)$ \\
\hline$\overline{\text { Coastal }}$ & 103 & 56 & 35 & 26 & 9.44 & 2 & 4.2 & 194 \\
\hline Hill & 284 & 195 & 63 & 52 & 24.32 & 11 & 19.7 & 48 \\
\hline Sal & 113 & 42 & 39 & 20 & 11.49 & 3 & 4.1 & 87 \\
\hline Sundarban & 28 & 19 & 15 & 12 & 2.19 & 1 & 1743.6 & 47 \\
\hline Village & 232 & 110 & 53 & 41 & 20.29 & 5 & 0.83 & 56 \\
\hline National & 392 & 278 & 71 & 63 & 29.37 & 12 & 166.2 & 45 \\
\hline
\end{tabular}


Table 4 Stand characteristics, volume, biomass and carbon stock estimates by zone (stratum). Standard error ( $\pm \%)$ is provided in (). Total carbon stock includes soil organic carbon up to $30 \mathrm{~cm}$

\begin{tabular}{|c|c|c|c|c|c|c|c|c|}
\hline Zone & $\begin{array}{l}\text { Tree density with } \\
\mathrm{DBH} \geq 10 \mathrm{~cm} \\
\left(\text { stem } \cdot \mathrm{ha}^{-1} \text { ) }\right.\end{array}$ & $\begin{array}{l}\text { Sapling density } \\
\text { with } 2 \mathrm{~cm} \leq \mathrm{DBH} \\
<10 \mathrm{~cm}\left(\text { stem }^{\prime} \mathrm{ha}^{-1}\right)\end{array}$ & $\begin{array}{l}\text { Basal } \\
\text { area } \\
\left(\mathrm{m}^{2} \cdot \mathrm{ha}^{-1}\right)\end{array}$ & $\begin{array}{l}\text { Gross } \\
\text { volume } \\
\left(\mathrm{m}^{3} \cdot \mathrm{ha}^{-1}\right)\end{array}$ & $\begin{array}{l}\text { Above ground } \\
\text { biomass } \\
\left(\mathrm{t} \cdot \mathrm{ha}^{-1}\right)\end{array}$ & $\begin{array}{l}\text { Below ground } \\
\text { biomass } \\
\left(\mathrm{t} \cdot \mathrm{ha}^{-1}\right)\end{array}$ & $\begin{array}{l}\text { Above } \\
\text { ground } \\
\text { carbon } \\
\left(\mathrm{t} \cdot \mathrm{ha}^{-1}\right)\end{array}$ & $\begin{array}{l}\text { Total } \\
\text { Carbon } \\
\text { (million } \mathrm{t} \text { ) }\end{array}$ \\
\hline Coastal & $229(25)$ & $740(51)$ & $8.82(20)$ & $50.08(23)$ & $43.63(20)$ & $8.31(20)$ & $21.79(20)$ & $47.43(7.04)$ \\
\hline Hill & $146(10)$ & 485 (16) & $6.23(10)$ & 47.69 (19) & $48.32(14)$ & $9.3(14)$ & $24.03(14)$ & $\begin{array}{l}199.83 \\
(3.95)\end{array}$ \\
\hline Sal & 169 (18) & $99(40)$ & $5.89(16)$ & 34.17 (17) & $59.43(17)$ & $10.18(17)$ & 31.36 (17) & $63.23(6.33)$ \\
\hline Sundarban & $661(9)$ & $6200(11)$ & $22.29(6)$ & $97.75(12)$ & 98.37 (8) & $66.06(7)$ & $49.28(8)$ & $66.04(3.40)$ \\
\hline Village & $98(12)$ & $86(21)$ & $3.28(10)$ & $21.44(11)$ & $20.66(10)$ & $3.98(11)$ & 10.47 (10) & $\begin{array}{l}899.02 \\
(2.87)\end{array}$ \\
\hline National & $129(8)$ & $344(9)$ & $4.52(6)$ & $28.54(8)$ & $28.78(7)$ & $6.91(6)$ & $14.55(7)$ & $\begin{array}{l}1275.55 \\
(2.16)\end{array}$ \\
\hline
\end{tabular}

income classes earn more from tree and forest products. Nowhere was the total annual income from trees and forests greater than in the Sundarbans periphery zone which stands at BDT 29,275 $\mathrm{HH}^{-1}$.year ${ }^{-1}$ (USD $347 \mathrm{HH}^{-1}$. year $^{-1}$ ), or $9 \%$ of the total income in that zone, an income earned mainly from selling fishery products (78\%).

\section{Discussion}

Sustainable forest management is at the core of forest planning and policy, and national forest monitoring provides the science-based information needed to implement and understand the impact of forest management plans (FAO 2017). To cope with increasing information needs and demand for expertise, comprehensive efforts need to be undertaken to strengthen capacities, including establishing a stable institutional setting for forest monitoring. Though the BFI is not yet fully institutionalized, strengthened national institutional partnerships contribute to improved forest monitoring by (1) defining and updating the objectives as stakeholder purposes and national priorities evolve, (2) building sustainability by sharing expertise and contributions, (3) contributing to the robustness of the results and recognition by national entities, (4) collecting field data through local stakeholder consultation particularly in unstable local political contexts, and (5) engaging youth. In addition, mobilising different technical expertise, such as forestry and remote sensing, contributes to its cost-effectiveness, e.g. reducing the cost and time related to data collection and processing.

Strengthened partnerships and stakeholder engagement contributes to increasing interest in the multiple uses of the datasets for planning and monitoring. As an example, the socio-economic and biophysical information about fuelwood demand and supply were used to assess access to wood fuel supply and support land restoration activities in Cox's Bazar district. The results were also used as baseline information in support of Investment Plans such as for the World Bank Forest Investment Program. In 2018, GoB confirmed its commitment to the plan by seeking an IDA credit of USD 175 million to finance the Sustainable Forests \& Livelihoods project. This contributes to the cross-sectoral Country Investment Plan for Environment, Forest and Climate Change (GoB 2017a). It responds to the urgent need to address environmental degradation and to improve the country's ability to meet the threats posed by climate change.

Common indicators developed through integration of socio-economic and biophysical variables and remote sensing, contributes to better understand drivers of environmental change and the interactions of human society and forest ecosystems. Though integration of natural and social sciences is already being applied (Mousavi and Alireza 2016; Westfall et al. 2018), their integration remains challenging. An enhanced consideration of the tree and forest ecosystem services and related information in the national statistics would contribute to overcoming some of the challenges related to data accessibility, linking area frames and list frames in ecosystemrelated socio-economic survey, and the completeness and robustness of the integrated approach of the BFI. The integration between field and remote sensing can improve the robustness of the results of the BFI by (1) improving the classification and proportioning techniques of the land features at plot and subplot level, (2) post-stratifying to improve estimates within zones, (3) integrating remote sensing parameters and field information, and (4) developing programs for monitoring and assessing land and multiple environmental functions (Corona 2010).

Classification of the land features on the ground, using fine-resolution aerial and satellite images, or following a hierarchical object-based approach using LCML (ISO 
2012), is not trivial and subject to classification/interpretation errors, particularly for a first NFI cycle. When comparing the classes assigned by field crews with the land cover map and aerial pictures, dissimilarities were as large as 38\% (Table S2.3). This can be related to the limited ability of the field crews to distinguish the different land classes in the field particularly when this depends on the size of land feature, land use and vegetation change (i.e., temporal and spatial dynamics) as illustrated in Fig. S3.1. In the south-eastern hill region, because of the lack of ground-based information due to inaccessibility, it was particularly difficult for the land cover mapping to distinguish classes such as shrub, forest and other vegetation forms. In a similar situation, the use of fine-resolution and multi-dated satellite data is recognized to result in better accuracy (Uddin et al. 2015). In the context of the broad ranges of classspecific accuracies of the remote sensing-based land cover map, we note that the reference classes were labelled using a pseudo-ground truth validation technique (Jalal et al. 2019) and were assumed to be correct considering the fact that reference classification error often occurs and may have implications for analysis of accuracy of land cover by remote sensing (Foody 2010). Another approach was tested using object-based classification of the land cover based on the descriptors collected by field crews. However, more data and research are needed to generate reliable results using this approach. Accordingly, the use of the land area estimates from the land cover map was preferred under this process considering it provided consistent wall-to-wall spatially explicit land cover information that could be used for the integration of the socio-economic and biophysical information. However, it is crucial for the next cycle to improve the classification of the land features on the ground by the field crews, the integration of the field and remote sensing information and the use of the accuracy assessment resulting in stratified land area estimates and associated uncertainty. Another option to improve the accuracy of the land area estimates is to use post-stratification within zones, which should be further investigated since it can be applied to permanent ground plots, while stratified random sampling cannot. Hewson et al. (2014) and Westfall et al. (2011) reported that the uncertainty due to post-stratification is only slightly larger than for stratification, particularly when there are at least 10 or more sample plots in each post-stratum. The accurate plot location of the BFI is useful to ensure the plots can be re-assigned unambiguously to remote sensing-based strata (Hewson et al. 2014). In addition, the increasing flow of temporally and spatially correlated multi-source data along with improved statistical approaches can meet the requirements of information about timber production and protection status of forests.

\section{Conclusion}

The BFI has provided national and sub-national estimates of key forest indicators for the period 2016 to 2019. Several innovations were introduced to ensure an efficient and repeatable national forest monitoring system that will help Bangladesh meet its natural resource-related targets and goals. The BFI has been established through a collaborative and participatory process in which the main governmental organisations, institutions, academia, research, NGOs and associations involved in tree, forest and natural resources monitoring were involved. This participatory process is crucial for supporting future needs as they arise, including capacity building and evolving national priorities.

Nonetheless, the full potential of the BFI will not be realized, and national needs will not be met, if the process is not supported by an institutionalized framework and regular budget allocation. Only in this way will the BFI be enable to continue enhancing collaboration, sharing data, exchanging information and experience, establishing the required agreements, and enhancing the research and development activities based on identified priorities such as related to SDGs, valuation of ecosystem services, and soil fertility among others. In the meantime, it is critical to disseminate the results and promote its value to society which will provide the support needed to justify a permanent national program.

\section{Supplementary Information}

The online version contains supplementary material available at https://doi. org/10.1186/s40663-021-00284-1.

Additional file 1: Supplementary information 1. $R$ scripts for the analysis of the first cycle of the Bangladesh Forest Inventory. 1. R-scripts for the data importation. 2. R-scripts for the preparation of databases. 3. R-scripts for the ratio estimations.

Additional file 2: Supplementary information 2. Additional tables provided as supplementary information. Table S2.1. Equations used as ratio-to-size estimators to estimate the biophysical indicators. Table S2.2. Total Carbon density by land cover in different zones. Table S2.3. Comparison between the classes identified from the land cover map and field observations.

Additional file 3: Supplementary information 3. An illustration of differences between land class identification and delineation using the land cover map and field observations. Figure S3.1. An illustration of differences between land class identification and delineation using the land cover map and field observations.

\section{Abbreviations}

BDT: Bangladeshi taka; BFI: Bangladesh forest inventory; CIP: Country investment plan; CV: Coefficient of variation; FAO: Food and agriculture organization of the United Nations; FD: Forest department; FGD: Focus group discussions; GPS: Global positioning system; HH: Household; LCC: Land cover class; LCCS: Land cover classification system; NFI: National forest inventory; NGO: Nongovernment Organization; QAVQC: Quality assurance and quality check; REDD+: Reducing emissions from deforestation and forest degradation, plus the sustainable management of forests, and the conservation and enhancement of forest carbon stocks; SDG: Sustainable development goals; UNCCD: United Nations convention to combat desertification; UNFCCC: United Nations framework convention on climate change 


\section{Acknowledgements}

The authors would like to express their profound gratitude to the various national and international entities which contributed to this process and in particular to the Bangladesh Forest Department, Government of the People's Republic of Bangladesh, for its leadership, USAID (GCP/BGD/058/USA) and UN-REDD programme (UNJP/BGD/057/ UNJ) for financial support, and FAO for technical assistance. The authors would like to acknowledge Antonio di Gregorio and Gianluca Franceschini for their support in preparing the national land representation system, Oswaldo Carrillo for data analysis and R scripts, Remi d' Annunzio, Marco Piazza and Stefano Ricci in deploying the Open Foris suite. The authors thank Daniel Wachira, Ikbal Faruk, Nasrin Akter, Mahbubur Rahman, Kamrul Hossain, Farah Tasnim, Nazrin Sultana, Shuhala Ahasan, Champa Rani Saha, Zarin Tasnim, Nandini Sarker, Tamanna Tabassum, Abdul Halim and other colleagues for their support throughout the process. The authors would like to express their gratitude and respect to the late Mizanur Rahman.

\section{Authors' contributions}

$\mathrm{MH}, \mathrm{ZI}, \mathrm{KJ}, \mathrm{MA}, \mathrm{LC}, \mathrm{RJ}$ contributed to the design, preparation,

implementation, analysis and preparation of the results. While CS, OK and LSA mostly contributed to the design of the biophysical component, NC, IA, SAK, FUA, SSH contributed to the socio-economic and RJ, RS, TA, MR contributed to the land cover component. LB, GS, BS, MFK, MR, TR, RM, SD, $A H B, H N, M M U, K M, M J, M M R, S N U, A K A, S M Z I$ and SH contributed to the implementation of the biophysical data component. NC, PC, Al, ARA and SH contributed to the implementation of the socio-economic component. MAH, MFK, HM, RM, MRHS, KM, and MMU contributed to the model development, data management and analysis. ZI, RM, LR, PM, KW and MS contributed to the institutional aspects of the process. LC, HH, FS, GS, LB, LC, MFK, NC contributed to the preparation of the training materials and manuals. The author(s) read and approved the final manuscript.

\section{Funding}

This study received financial support from projects GCP/BGD/058/USA and UNJP/BGD/057/UNJ.

\section{Availability of data and materials}

Not applicable.

\section{Ethics approval and consent to participate}

Not applicable.

\section{Consent for publication}

Not applicable.

\section{Competing interests}

The authors declare that they have no competing interests.

\section{Author details}

${ }^{1}$ Food and Agriculture Organization of the United Nations, Viale delle Terme di Caracalla, 00153 Rome, Italy. ${ }^{2}$ Forest Department, Ministry of Environment, Forests and Climate Change, Ban Bhaban, Shere Bangla Nagar, Agargaon, Dhaka 1207, Bangladesh. ${ }^{3}$ School of Ecosystem and Forest Sciences, University of Melbourne, Parkville Victoria, Melbourne 3010, Australia. ${ }^{4}$ United States Forest Service (USFS) / SilvaCarbon, Washington, D.C, USA. Institute of Forestry and Environmental Sciences (IFES), University of Chittagong, Chattogram, Bangladesh. ${ }^{6}$ Department of Forestry and Environmental Science, Rangamati Science and Technology University, Rangamati, Bangladesh. 'Forestry and Wood Technology Discipline, Khulna University, Khulna, Bangladesh. ${ }^{8}$ School of Biological Sciences, The University of Queensland, QLD, Brisbane 4072, Australia. ${ }^{9}$ Arannyak Foundation, Dhaka, Bangladesh. ${ }^{10}$ United Nations Framework Convention on Climate Change (UNFCCC), Bonn, Germany. ${ }^{11}$ Bangladesh Space Research and Remote Sensing Organization (SPARRSO), Dhaka, Bangladesh. ${ }^{12}$ Institute for Marine Research and Observation, Ministry of Marine Affairs and Fisheries, Negara, Bali, Indonesia. ${ }^{13}$ Department of Agricultural Economics, Bangabandhu Sheikh Mujibur Rahman Agricultural University (BSMRAU), Gazipur, Bangladesh. ${ }^{14}$ Bangladesh Bureau of Statistics (BBS), Dhaka, Bangladesh. ${ }^{15}$ Institute of Statistical Research and Training, University of Dhaka, Dhaka, Bangladesh. ${ }^{16}$ United States Agency for International Development (USAID),
Dhaka, Bangladesh. ${ }^{17}$ Department of Forestry and Environmental Science, Shahjalal University of Science and Technology, Kumargaon, Sylhet, Bangladesh. ${ }^{18}$ Department of Biological Sciences, Faculty of Science and Engineering, Macquarie University, Sydney, Australia. ${ }^{19}$ Bangladesh National Herbarium (BNH), Zoo Road, Mirpur, Dhaka, Bangladesh. ${ }^{20}$ Bangladesh Forest Research Institute (BFRI), Sholoshahar, Chottogram, Bangladesh. ${ }^{21}$ National Research Institute for Agriculture, Food and Environment (INRAE), Paris, France.

Received: 30 April 2020 Accepted: 13 January 2021

Published online: 07 February 2021

\section{References}

Arnold FE, Rametsteiner E, Kleinn C (2014) User-oriented national forest monitoring planning: a contribution to more policy relevant forest information provision. Int For Rev 16:389-404. https://doi.org/10.1505/ 146554814813484059

Baatz M, Schäpe A (2000) Multiresolution segmentation: an optimization approach for high quality multi-scale image segmentation. In: Strobl J, Blaschke T, Griesebner G (eds) Angewandte Geographische Informations-Verarbeitung. XII. Wichmann Verlag, Karlsruhe, Germany, pp 12-23

BBS (2015) Bangladesh population and housing census 2011. Bangladesh Bureau of Statistics, Dhaka, Bangladesh

BSGI FD (2016) Protocol for describing land features in Bangladesh. Bangladesh Society of Geoinformatics, Forest Department, Ministry of Environment, Forest and Climate Change, Dhaka, Bangladfesh

Castilla G, Hay GJ (2008) Image objects and geographic objects. In: Castilla G, Hay GJ (eds) Object-based image analysis: spatial concepts for knowledge-driven remote sensing applications. Springer, Berlin Heidelberg, Berlin, Heidelberg, pp 91-110

Cochran WG (1977) Sampling techniques, third edn. John Willey \& Sons, New York

Corona P (2010) Integration of forest mapping and inventory to support forest management. Iforest Biogeosci For 3:59-64. https://doi.org/10. 3832/ifor0531-003

Costello L, Piazza M (2015) Proceedings from the training survey design and data management using open Foris collect for NFI and carbon stock assessment in Bangladesh. Forest Department, Ministry of Environment, Forest and Climate Change, Dhaka, Bangladesh, p 17

Costello L, Piazza M, Iqbal Z, Nur Siddiqui B, Akhter M, Siddiqui R, Henry M (2016) Experiences in field missions to locate the plots of the 2005 National Forest Assessment of Bangladesh. Forest Department, Ministry of Environment, Forest and Climate Change, Dhaka, Bangladesh, p 12

De Lange WJ, Wise RM, Forsyth GG, Nahman A (2010) Integrating socioeconomic and biophysical data to support water allocations within river basins: an example from the Inkomati water management area in South Africa. Environ Model Softw 25:43-50. https://doi.org/10.1016/j.envsoft. 2009.06.011

Dhali HH (2008) Deforestation and its impacts on indigenous women: a case from the Chittagong hill tracts in Bangladesh. Gend Technol Dev 12:229-246. https://doi.org/10.1177/097185240801200204

Di Gregorio A, Leonardi U (2016) Land cover classification system software version 3 - user manual. Food and agriculture Organization of the United Nations, Rome, Italy

Donato DC, Iqbal Z (2011) Carbon assessment report 2009-2010 inventory of the Sundarbans reserve Forest. Dhaka, Bangladesh and Washington D.C., United States of America

Dubovyk O (2017) The role of remote sensing in land degradation assessments: opportunities and challenges. Eur J Remote Sens 50:601-613. https://doi.org/ $10.1080 / 22797254.2017 .1378926$

FAO (2010) Global Forest resources assessment 2010 Main report. Food and agriculture Organization of the United Nations, Rome, Italy

FAO (2015a) Global Forest resources assessment 2015. Food and agriculture Organsiation of the United Nations, Rome, Italy

FAO (2015b) Knowledge reference for national forest assessment. Food and agriculture Organization of the United Nations, Rome, Italy

FAO (2017) Voluntary guidelines on National Forest Monitoring. Food and agriculture Organization of the United Nations, Rome, Italy

FAO (2018a) Open Foris collect Mobile handbook. Food and agriculture Organization of the United Nations, Rome, Italy 
FAO (2018b) Global Forest resource assessment 2020- guidelines and specifications. Food and agriculture Organization of the United Nations, Rome, Italy

FD (2016a) Bangladesh forestry master plan (2017-2036) (draft final). Forest Department, Ministry of Environment, Forest and Climate Change, Dhaka, Bangladesh

FD (2016b) The Bangladesh forest inventory design: methodological approach. Forest Department, Ministry of Environment, Forest and Climate Change, Dhaka, Bangladesh

FD (2016c) Quality assurance and quality control for the Bangladesh Forest inventory. Forest Department, Ministry of Environment, Forest and Climate Change, Dhaka, Bangladesh

FD (2017a) Field instructions for the Bangladesh Forest inventory socioeconomic survey. Forest Department, Ministry of Environment, Forest and Climate Change of Bangladesh, Dhaka

FD (2017b) Socioeconomic Field Instructions for the Enumerators of Bangladesh Forest Inventory. Forest Department, Ministry of Environment, Forests and Climate Change of Bangladesh, Food and Agriculture Organization of the United Nations, Dhaka, Bangadesh

FD (2019) Bangladesh Forest Information System. http://bfis.bforest.gov.bd/bfis/. Accessed 30 Apr 2020

FD, FAO (2007) National forest and tree resources assessment 2005-2007 Bangladesh. Forest Department Ministry of Environment. Forest and Climate Change and Food and Agriculture Organization of the United Nations, Dhaka, Bangladesh and Rome, Italy

Foody GM (2010) Assessing the accuracy of land cover change with imperfect ground reference data. Remote Sens Environ 114:2271-2285. https://doi.org/ 10.1016/j.rse.2010.05.003

Forestal (1960) Forest Inventory 1958-59 Sundarbans Forests, volume 1. Forestry and Engineering International Ltd., Vancouver

GED (2015) Seventh Five Year Plan, FY2016 - FY2020, Accelerating Growth, Empowering Citizens. General Economics Division (GED), Planning Commission, Government of the People's Republic of Bangladesh, Dhaka

GED (2018) Sustainable development goals: Bangladesh Progress report. General Economics Division, Bangladesh Planning Commission, Ministry of Planning, Dhaka, Bangladesh

GoB (2017a) Country investment plan on environment, forestry and climate change. The Ministry of Environment, and Forest and Climate Change, Dhaka Bangladesh

GoB (2017b) Criteria and indicators of Bangladesh Forest inventory: integration of socio-economic and biophysical information. Forest Department, Ministry of Environment, Forest and Climate Change, Dhaka

GoB (2017c) The socio-economic survey design of the Bangladesh Forest inventory. Forest Department, Ministry of Environment, Forest and Climate Change, Dhaka, Bangladesh

GoB (2017d) Land representation system of Bangladesh (in support of REDD+). Forest Department, Ministry of Environment, Forest and Climate Change, Government of the People's Republic of Bangladesh, Dhaka, Bangladesh

GoB (2020a) SDG Tracker Bangladesh's Development Miror. https://sdg.gov.bd/. Accessed 20 Jul 2020

GoB (2020b) Land cover atlas of Bangladesh 2015 (in support of REDD+). Forest Department, Ministry of Environment, Forest and Climate Change, Government of the People's Republic of Bangladesh, Dhaka, Bangladesh

GoB (2019) Tree and forest resources of Bangladesh: Report on the Bangladesh Forest Inventory. Forest Department, Ministry of Environment, Forest and Climate Change, Government of the People's Republic of Bangladesh, Dhaka. http://bfis.bforest.gov.bd/bfi/wp-content/uploads/2020/08/BFI_report_ final_8-12-20_2.pdf.

Hasnat GNT, Kabir MA, Hossain MA (2018) Major environmental issues and problems of South Asia, particularly Bangladesh. In: Hussain CM (ed) Handbook of environmental materials management. Springer, Switzerland, pp 1-40

Hewson J, Steininger MK, Pesmajoglou S (2014) REDD+ measurement, reporting and verification (mrv) manual, version 2.0. USAID-supported Forest carbon, markets and communities program, Washington D.C., United States of America

Hossain M (2016) Improved National Tree Allometric Equation Database to support Forest monitoring and assessment of Bangladesh. Forest Department, Ministry of Environment, Forest and Climate Change, Forestry and Wood Technology Discipline, Khulna University, Dhaka and Khulna, Bangladesh

Hossain M, Siddique MMA (2016) A critical review and database of biomass and volume allometric equation for trees and shrubs of Bangladesh. Int Conf Water Resour Environ:34. https://doi.org/10.1088/1755-1315/39/1/012057
Hossain MA, Anik AR, Chakma N, Johnson K, Henry M, Jalal R, Carrillo O, Scott C, Birigazzi L, Akhter M, lqbal Z (2019) Estimation procedures of indicators and variables of the Bangladesh Forest inventory. Forest Department, Ministry of Environment, Forest and Climate Change, Dhaka

Iftekhar MS, Saenger P (2008) Vegetation dynamics in the Bangladesh Sundarbans mangroves: a review of forest inventories. Wetl Ecol Manag 16: 291-312. https://doi.org/10.1007/s11273-007-9063-5

ISO (2012) Geographic information - classification systems - part 2: land cover Meta language (LCML). International Standard Organisation, Geneva, Switzerland

Jalal R, labal Z, Henry M, Franceschini G, Islam MS, Akhter M, Khan ZT, Hadi MA, Hossain MA, Mahboob MG, Udita TS, Aziz T, Masum SM, Costello L, Saha CR, Chowdhury AAM, Salam A, Shahrin F, Sumon FR, Rahman M, Siddique MA, Rahman MM, Jahan MN, Shaunak MF, Rahman MS, Mohammd I, Mosca N, D’Ánnunzio R, Hira S, Gregorio AD (2019) Toward efficient land cover mapping: an overview of the national land representation system and land cover map 2015 of Bangladesh. IEEE J Sel Top Appl Earth Obs Remote Sens 12:3852-3861. https://doi.org/10.1109/JSTARS.2019.2903642

Julve Larrubia C, Ross K, Wolfslehner B, Guldin R, Rametsteiner E (2017) Using criteria and indicators for sustainable forest management. A way to strengthen results-based management of national forest programmes. Food and Agriculture Organization of the United Nations, Rome, Italy

Kleinn C (2017) The renaissance of National Forest Inventories (NFIs) in the context of the international conventions - a discussion paper on context, background and justification of NFls. Braz J For Res. https://doi.org/10.4336/ 2017.pfb.37.91.1343

Korhonen KT, Salmensuu O (2014) Formulas for estimators and their variances in NFI. Internal report. United States Department of Agriculture, Washington, D. C., United States of America

Margalef R (1958) Information theory in biology. Gen Syst 3:36-71

Mensah J, Casadevall SR (2019) Sustainable development: meaning, history, principles, pillars, and implications for human action: literature review. Cogent Soc Sci 5:1653531-undefined. doi:https://doi.org/10.1080/23311886. 2019.1653531

MoEFCC (2018) The submission of Bangladesh's Forest reference level for REDD+ under the UNFCCC. Ministry of Environment, Forest and Climate Change (MoEFCC), Dhaka

Mojid MA (2020) Climate change-induced challenges to sustainable development in Bangladesh. IOP Conf Ser Earth Environ Sci 423:12001. https://doi.org/10. 1088/1755-1315/423/1/012001

Mousavi FJP, Alireza S (2016) Integrating socio-economic and biophysical data to enhance watershed management and planning. J Hydrol 540:727-735

Olofsson P, Foody GM, Stehman SV, Woodcock CE (2013) Making better use of accuracy data in land change studies: estimating accuracy and area and quantifying uncertainty using stratified estimation. Remote Sens Environ 129: 122-131. https://doi.org/10.1016/j.rse.2012.10.031

Potapov P, Siddiqui BN, Iqbal Z, Aziz T, Zzaman B, Islam A, Pickens A, Talero Y, Tyukavina A, Turubanova S, Hansen MC (2017) Comprehensive monitoring of Bangladesh tree cover inside and outside of forests, 2000-2014. Environ Res Lett 12:104015. https://doi.org/10.1088/1748-9326/aa84bb

Rahman MM, Jashimuddin M (2017) Socioeconomic survey Design of the Bangladesh Forest Inventory. Forest Department, Ministry of Environment, Forest and Climate Change, Dhaka

Reddy CS, Pasha SV, Jha CS, Diwakar PG, Dadhwal VK (2016) Development of national database on long-term deforestation (1930-2014) in Bangladesh. Glob Planet Change 139:173-182. https://doi.org/10.1016/j.gloplacha.2016.02.003

Scott CT (1993) Optimal design of a plot cluster for monitoring. In: Keith R, George $\mathrm{G}$ (eds) The Optimal Design of Forest Experiments and Forest Surveys, Proceedings. IUFRO S.4.11 Conference. University of Greenwich, London, UK, pp 233-242

Scott CT (2018) Estimation using ratio-to-size estimator across strata and subpopulations. https://www.scribd.com/document/388141246/EstimationUsing-Ratio-To-Size-Estimator-Across-Strata-and-Subpopulations-2018-04-18. Accessed 30 Apr 2020

Scott CT, Bush R, Brewer K (2009) Design tool for inventory and monitoring. In: McWilliams W, Gretchen M, Ray C (eds) Forest inventory and analysis (FIA) symposium 2008. USDA Forest Service, Rocky Mountain Research Station, Fort Collins, pp 230-237

Tewari VP (2016) Forest inventory, assessment, and monitoring, and long-term forest observational studies, with special reference to India. Forest Sci Technol 12:24-32. https://doi.org/10.1080/21580103.2015.1018962 
Thompson SK (2012) Sampling, 3rd edn. John Wiley \& Sons, Hoboken, New Jersey, United States of America

Uddin K, Shrestha HL, Murthy MSR, Bajracharya B, Shrestha B, Gilani H, Pradhan S, Dangol B (2015) Development of 2010 national land cover database for the Nepal. J Environ Manag 148:82-90

Uddin MM, Al MMA, Jannat M (2019) Impacts of mangrove plantations on land stabilization along the coastline in Bangladesh. Am J Earth Environ Sci 2:1-8 Udita T, Franceschini G, Jalal R, Akhter M (2016) Proceedings of the working sessions on supporting the preparation of the land cover map development and the integration of land cover and Forest monitoring. Forest Department, Ministry of Environment, Forest and Climate Change, Dhaka, p 19

UN (2015) Resolution adopted by the General Assembly on 25 September 2015, Transforming our world: the 2030 Agenda for Sustainable Development (A) RES/70/1). United Nations, New York

UNDESA (2019) World population prospects 2019, ST/ESA/SER.A/424. New York Westfall JA, Patterson PL, Coulston JW (2011) Post-stratified estimation: with-in strata and total sample size recommendations. Can J For Res 41:1130-1139

Westfall JA, Patterson PL, Edgar CB (2018) Integrating urban and national forest inventory data in support of rural-urban assessments. For An Int J For Res 91:641-649. https://doi.org/10.1093/forestry/cpy023

Zeng W, Tomppo E, Healey SP, Gadow KV (2015) The national forest inventory in China: history - results - international context. For Ecosyst 2:23. https://doi. org/10.1186/s40663-015-0047-2

\section{Submit your manuscript to a SpringerOpen ${ }^{\circ}$ journal and benefit from:}

- Convenient online submission

- Rigorous peer review

- Open access: articles freely available online

- High visibility within the field

- Retaining the copyright to your article

Submit your next manuscript at $\boldsymbol{\nabla}$ springeropen.com 